OPEN ACCESS

Edited by:

Martin Huelskamp,

University of Cologne, Germany

Reviewed by:

Alice Y. Cheung,

University of Massachusetts Amherst,

USA

Tetsuya Higashiyama,

Nagoya University, Japan

*Correspondence:

Silvia Coimbra

scoimbra@fc.up.pt

Specialty section: This article was submitted to

Plant Cell Biology,

a section of the journal

Frontiers in Plant Science

Received: 29 August 2016 Accepted: 30 November 2016 Published: 16 December 2016

Citation:

Pereira AM, Lopes AL and Coimbra S (2016) Arabinogalactan

Proteins as Interactors along the Crosstalk between the Pollen

Tube and the Female Tissues.

Front. Plant Sci. 7:1895

doi: 10.3389/fpls.2016.01895

\section{Arabinogalactan Proteins as Interactors along the Crosstalk between the Pollen Tube and the Female Tissues}

\author{
Ana M. Pereira ${ }^{1,2}$, Ana L. Lopes ${ }^{1,2}$ and Sílvia Coimbra ${ }^{1,2 *}$ \\ ${ }^{1}$ Departamento de Biologia, Faculdade de Ciências da Universidade do Porto, Porto, Portugal, ${ }^{2}$ Biosystems and Integrative \\ Sciences Institute, Porto, Portugal
}

Arabinogalactan proteins (AGPs) have long been considered to be implicated in several steps of the reproductive process of flowering plants. Pollen tube growth along the pistil tissues requires a multiplicity of signaling pathways to be activated and turned off precisely, at crucial timepoints, to guarantee successful fertilization and seed production. In the recent years, an outstanding effort has been made by the plant reproduction scientific community in order to better understand this process. This resulted in the discovery of a fairly substantial number of new players essential for reproduction, as well as their modes of action and interactions. Besides all the indications of AGPs involvement in reproduction, there were no convincing evidences about it. Recently, several studies came out to prove what had long been suggested about this complex family of glycoproteins. AGPs consist of a large family of hydroxyproline-rich proteins, predicted to be anchored to the plasma membrane and extremely rich in sugars. These two last characteristics always made them perfect candidates to be involved in signaling mechanisms, in several plant developmental processes. New findings finally relate AGPs to concrete functions in plant reproduction. In this review, it is intended not only to describe how different molecules and signaling pathways are functioning to achieve fertilization, but also to integrate the recent discoveries about AGPs along this process.

Keywords: plant reproduction, arabinogalactan proteins, pollen tube guidance, signaling, double fertilization

\section{ARABINOGALACTAN PROTEINS - THE FORGOTTEN ONES}

The importance of the reproductive process for seed formation in flowering plants is, nowadays, unquestionable. This is a complex mechanism involving a series of signaling pathways with plenteous of well described players. The advances, made by live cell imaging and microscopy techniques allowed for a better understanding about how fertilization occurs. But classical reverse and forward genetics studies, microscopy ultrastructural analysis as well as the analyses of big data from microarrays or RNA-sequencing are still indispensable techniques for the discovery of new players and interactors with the already known molecules.

A big family of proteins that was always suggested to be involved in the reproductive process, since the formation of the gametophytes until fertilization is the Arabinogalactan protein (AGP) family. More recently, their functions in reproduction started to be unraveled, as well as their 
enigmatic mode of action. AGPs are a big family of hydroxyproline-rich glycoproteins, predicted to be tethered to the plasma membrane by a glycosylphosphatidylinositol (GPI) anchor (Schultz et al., 2002; Borner et al., 2003; Nguema-Ona et al., 2014). AGPs are composed primarily of carbohydrates surrounding a small proteinaceous core (Seifert and Roberts, 2007). These glycoproteins are suggested to play important functions in plants as signaling molecules given their particular characteristics: (1) GPI-anchor- which is a possible mode of release of these molecules to the extracellular medium where they may exert their functions, similar to what happens with the glycoprotein SKU5 (Sedbrook et al., 2002); (2) the high diversity of glycans decorating AGPs are also strong candidates to be released by proper enzymes and act as signaling molecules themselves. Sugar signaling in plants is only starting to be elucidated, much studies are required to fully understand how they act and are integrated in the several signal transduction pathways (Li and Sheen, 2016).

Recently Showalter et al. (2010) conducted a bioinformatic analysis identifying 85 AGPs in Arabidopsis, belonging to different sub-groups. According to their amino acidic composition AGPs can be classified as classical AGPs: Lysinerich classical AGPs and arabinogalactan (AG) peptides; and chimeric AGPs: fasciclin-like AGPs (FLAs), plastocyanin AGPs, and other chimeric AGPs.

Several studies, in the most recent years, have contributed to unravel the mysterious mode of action of AGPs, supporting the hypothesis that AGPs carbohydrate components are AGPs' main interacting and active constituents (Basu et al., 2013, 2015a,b; Ogawa-Ohnishi and Matsubayashi, 2015).

In these review we describe not only some of the already known molecules involved in plant reproduction, but we also integrate AGPs findings along the different phases of this process.

\section{RISING THE FOUNDATIONS OF A LOVE STORY}

Double fertilization is a key process for successful development of a seed and the establishment of a new plant generation. It is a unique process, characteristic of Angiosperms, where two fertilizations occur simultaneously. This process was first described by S. Nawaschin in Lilium martagon and Fritillaria tenella in 1898. L. Guinard has confirmed the same phenomenon 1 year later, in 1899, independently, in L. martagon e L. pyrenaicum (Raghavan, 2003).

In flowering plants, the male gametophyte develops inside the anthers locules (Figure 1A), part of the stamen, the male reproductive organ. It is released as a mature pollen grain containing a vegetative cell that will develop into a pollen tube and a generative cell that will generate by mitosis two sperm cells: the male gametes (McCormick, 2004; Borg and Twell, 2010).

The female gametophyte develops inside the ovule, deeply embedded in the sporophytic tissues of the pistil (Figure 1B). During megasporogenesis a cell from the nucellus, the archesporial cell, differentiates into the megaspore mother cell, which undergoes meiosis giving rise to four haploid megaspores. One of these megaspores develops into the functional megaspore and the remaining three megaspores will undergo programmed cell death (PCD). In the Polygonumtype of female gametophyte (Yadegari and Drews, 2004), the functional megaspore undertakes three rounds of nuclear divisions (mitosis without cytokinesis) resulting in a coenocyte with eight nuclei at distinct positions of the female gametophyte. After migration of the nuclei and cellularization, the mature embryo sac or female gametophyte is formed, a seven celled, eight-nucleated structure that comprises: three antipodal cells positioned in the chalazal pole of the ovule, one diploid central cell and two synergid cells surrounding the egg cell, at the micropylar pole of the ovule. Here are kept the two female gametes: the central cell and the egg cell (Huang and Russell, 1992; Drews et al., 1998; Yadegari and Drews, 2004).

Pennell and Roberts (1990) had foreseen that in Pisum sativum, the switch from a vegetative to a reproductive stage of development was related with the presence or absence of arabinose-containing epitopes identified by the monoclonal antibody MAC207 (Pennell et al., 1989), describing these AGPs epitopes only in the sporophytic tissues. Later, a new monoclonal antibody characterized by Pennell et al. (1991), JIM8, recognized AGP sugar epitopes also during the gametophytic phase of development: in sperm cells, egg cells and in the synergids filiform apparatus in Brassica napus flowers. Coimbra et al. (2007) using several anti-AGP antibodies, identified AGPspecific sugar epitopes in the functional megaspore and in the female gametophyte: synergid cells and in the synergid filiform apparatus of Arabidopsis, confirming the previous immunolocalization studies and the concept of differential expression of AGPs in plant reproductive tissues.

Later, AGP18 was identified as an AGP essential for female gametophyte formation (Acosta-García and Vielle-Calzada, 2004; Demesa-Arévalo and Vielle-Calzada, 2013). AGP18 was shown to be transcribed specially in the megaspore mother cell, but its glycosylation pattern was only defined in the functional megaspore, confirming the importance of AGPs in cell fate determination. This also revealed that the full activation of AGPs function in diferent tissues is dependent on the presence of specific glycosylation enzymes at particular developmental timings, and pinpoint their importance as potential cell fate determination factors as suggested by Pennell et al. (1991). Tucker et al. (2012) and Tucker and Koltunow (2014) also focused on the importance of other AGPs such as AGP22 and AGP24, in the megaspore mother cell and in the functional megaspore formation and development. Yellow fluorescent protein expression driven by AGP22 and AGP24 promoters targeted the nucellar epidermal cells and the functional megaspore, respectively, supporting the immunolocalization studies made with JIM13 by Coimbra et al. (2007), and their possible roles as cell fate determination factors.

Immunolocation has been widely used as the main tool to study AGPs localization (Pereira et al., 2015). Even if the antibodies are directed to the glycosidic moiety and do not recognize a specific AGP, they are still valuable tools to dissect functions, as demonstrated by the studies described above. These have shown the importance of AGPs in the differentiation 

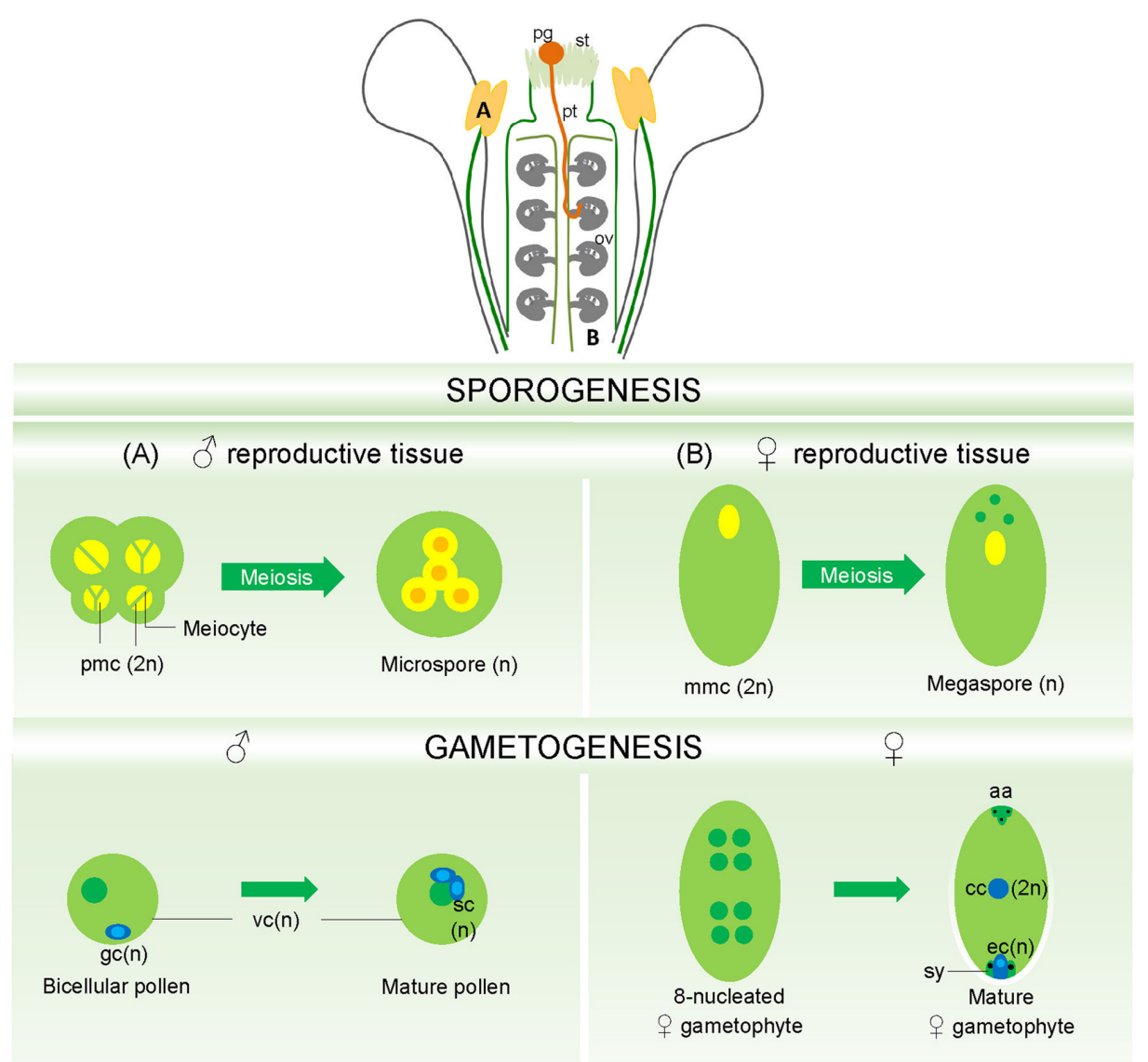

FIGURE 1 | Mature flower showing in detail male and female gametophyte's formation. (A) The pollen mother cells, located inside the anther locules, undergo meiosis generating the haploid microspores in a process called sporogenesis. Sporogenesis is followed by gametogenesis, where a mature pollen is formed, containing a vegetative cell engulfing two sperm cells, the male gametes. (B) The megaspore mother cells embedded in the ovular nucellar tissues also undergoes meiosis generating four haploid megaspores. From these, only one will survive and become the functional megaspore, which, after three rounds of mitosis and cellularization will give rise to the mature female gametophyte, the embryo sac. ov, ovule; pg, pollen grain; pt, pollen tube; st, stigma; pmc, pollen mother cell; mmc, megaspore mother cell; gc, generative cells; vc, vegetative cells; sc, sperm cells; cc, central cell; ec, egg cell; sy, synergids; aa, antipodals. (Mature flower reproduced with permission from Pereira et al., 2014).

of the functional megaspore, which gives rise to the female gametophyte. AGPs localization studies using classical molecular tools are still poorly explored due to the complexity of these molecules. The putative presence of a GPI anchor and the high amount of carbohydrate chains makes it difficult to obtain a stable construct expressing a reporter gene. This may lead to conformational changes that will affect the glycoprotein activity. So far, most of the AGPs localization studies with reporter genes such as the green fluorescent protein or the $\beta$-glucuronidase, have been made using only the respective AGP promoter region, allowing us to access only its localization in diferent tissues and cell types, but not their intracellular location (Pereira et al., 2014).

\section{DOUBLE FERTILIZATION - TWOSOMES, A LOVE STORY}

When a mature pollen grain finally reaches the stigmatic cells and is recognized as compatible pollen, it adheres to the stigmatic cell and hydration begins, leading to the formation of a protrusion. This protrusion will become the pollen tube that is responsible for carrying the two sperm cells into the embryo sac. The fast and tightly controlled growth of the pollen tube tip is ensured by a series of communication and consequent signaling cascades, which result from several interactions between the pollen grain and the pollen tube with the female sporophytic and gametophytic tissues. Given this, the pollen tube tip grows along the extracellular matrix of the stylar and transmitting tract tissues until it perceives signals that will make it turn abruptly in the direction of an ovule. At this moment the pollen tube quickly turns into the placenta tissues, growing along the funiculus until it reaches the embryo sac entrance: the micropyle. Once in the micropylar region the pollen tube enters the embryo sac through the filiform apparatus of one of the two synergids, ceasing its growth, rupturing and releasing its two sperm cells. The invaded synergid dies after pollen tube entrance, and the persisting synergid will undergo synergid-endosperm fusion after successful fertilization of both female gametes. The sperm cells 
migrate to the egg and central cell, and fuse with them, giving rise, respectively, to the embryo and the nourishing tissue, the endosperm, finally accomplishing double fertilization (reviewed in Palanivelu and Tsukamoto, 2012; Beale and Johnson, 2013; Dresselhaus and Franklin-Tong, 2013).

Recently, the knowledge developed on peptide signaling became crucial to understand the molecular mechanisms along the pollen tube journey and during double fertilization. Secreted peptides of various cysteine-rich peptides (CRPs) subclasses were identified as players in pollen grain recognition at the stigma, in pollen tube growth support and guidance, in attracting the tube to enter the embryo sac and in gamete interaction mediation $(\mathrm{Qu}$ et al., 2015).

Large gene families of peptides are involved in double fertilization and most members show similar expression patterns with redundant function, as shown in studies of EC1s (Sprunck et al., 2012), LUREs (Takeuchi and Higashiyama, 2012), and ES1-4 (Amien et al., 2010; Woriedh et al., 2015). CRP subfamilies like LTPs (lipid-transfer proteins) and RALFs (RAPID ALKALINIZATION FACTOR) are strongly expressed along the pollen tube pathway, and some functions are starting to be revealed. As indicated by Bircheneder and Dresselhaus (2016), RALF peptides secreted from the pollen tube may act as pollen-derived interaction partners of synergid-localized FER (FERONIA) to induce male-female communication events. Like this, other intensive communication takes place during the pollen tube journey within the maternal tissues of the stigma, style, transmitting tract and ovule. These processes have been recently fairly reviewed (Palanivelu and Tsukamoto, 2012; Dresselhaus and Franklin-Tong, 2013; Bleckmann et al., 2014; Higashiyama and Takeuchi, 2015; Qu et al., 2015; Dresselhaus et al., 2016) although not enough attention was given to AGPs as basal component interactors.

The following sections highlight several communication steps between the male gametophyte and the female reproductive tissues: (i) interaction events during the growth of the pollen tube throughout the female flower tissues, (ii) molecular mechanisms during pollen tube reception, and (iii) double fertilization and multiple pollen tube blockage.

\section{POLLEN TUBE GERMINATION AND GROWTH - THE LOVE STORY BEGINS}

Pollen tube growth from the stigma until the embryo sac may be divided in two different phases:

- A sporophytic phase, that comprises pollen tube growth from the stigma, through the style and the transmitting tract, and independent from molecular cues from the FG;

- A gametophytic phase, which depends also on molecular cues provided by the FG, and refers to pollen tube growth from the moment it makes a quick turn into the septum surface and enters the funiculus targeting the micropyle of the embryo sac.

The sprorophytic phase starts with pollen grain in the stigma, the initial adhesion of the pollen grain to the stigma surface is largely dependent on the outer wall of the pollen grain, the exine (Zinkl et al., 1999). Immediately after contact with stigmatic cells, the pollen coat is extruded of the exine wall against the stigma surface, forming a 'foot' that strongly sticks to the stigma (Chapman and Goring, 2010). Hydration of the pollen grain follows this step, depending on the pollen coat lipids to control the movement of water from the stigma (Wolters-Arts et al., 1998; Mayfield and Preuss, 2000; Mayfield et al., 2001).

Though the pollen grain has great responsibility in initiating compatible pollen grain germination in the stigma (reviewed in Doucet et al., 2016), its female partner is also essential for this successful interaction. Exo70A1, an exocyst complex subunit present in Arabidopsis thaliana stigmas is needed for acceptance of compatible pollen grain. Exo70A1 is proposed to act in the polarized secretion of stigmatic cells to deliver vesicles containing aquaporins for increased water permeability, allowing pollen hydration, as well as cell wall-modifying enzymes, to allow pollen tube penetration through the stigma (Samuel et al., 2009). Through the study of mutants with reduced levels of phosphatidylinositol-4-phosphate (PI4P) in the stigma, PI4P was also shown to be essential for this initial step of pollen-pistil interaction. These mutants revealed slower rates of pollen grain hydration and showed maternal fertility defects due to a higher level of failed pollinations (Chapman and Goring, 2011). This study suggested that phosphoinositides, which are important lipids involved in polarized secretion in general, have a specific role in pollen hydration. Although in animals and yeast, the Exo70A1 is proposed to bind PIP4, 5 $\mathrm{P}_{2}$ (He et al., 2007; Liu et al., 2007) defining the location of the exocyst assembly, this study didn't show the same mode of action in plants.

Pollen tube-female tissues interactions entail intercellular communication between different cell types, requiring the compartmentalization and degradation of signaling molecules and, many times, the continuation or starting of the signaling pathway after internalization, as well as the recycling of cell wall molecules, via the endocytic pathway. An A. thaliana Vacuolar Protein Sorting 41 (AtVPS41) was very recently identified as being a new factor controlling pollen tube-stigma interaction (Hao et al., 2016). Atvps41 pollen tubes fail to penetrate the female transmitting tract due to an impairment in the endocytic pathway.

Arabinogalactan proteins are present in the stigma cells and in the growing pollen tubes, thus suggesting possible roles for them in pollen-stigma cells interactions, and acquisition of pollen grain competence to initiate pollen tube growth. AGP6 and AGP11, pollen specific AGPs, were shown to be involved in the pollen tube endosome machinery (Costa et al., 2013). Yeast-2Hybrid experiments made with these two AGPs showed their physiological interaction with several members of the endosomal system. As suggested in the above studies, the pollen tube interactions with the female tissues requires constant integration of signaling molecules from the extracellular matrix, degradation and/or recycling of these molecules, and in the case of AGPs, their internalization and secretion through multivesicular bodies (MVBs) (Costa et al., 2013). This is coherent with Pereira et al. (2006) results, where the site of pollen tube emergence was labeled with MAC207 by immunolocalization, an antibody 
that recognizes AGPs carbohydrate epitopes. This antibody labeled the growing pollen tube after germination. When using a different antibody, LM2, which recognizes other AGPs specific carbohydrates, the labeling was different, restricted to a "collar-like" shape in the emerging pollen tube. Dardelle et al. (2010) confirmed these results, showing that LM2 also has a stronger labeling at the pollent tube tip, where a highly dynamic intracellular trafficking occurs targeting the transport of vesicles. Clearly, polar pollen tube growth involves the integration of several signal transduction pathways through the membrane and the cell wall, where AGPs appear to be involved, greatly controlled by the regulation of vesicle trafficking.

$\mathrm{Ca}^{2+}$ is an important signaling molecule during pollen tube growth along the pistil tissues. Monitoring of $\mathrm{Ca}^{2+}$ dynamics during pollination both in pollen grain and stigmatic cells revealed some interesting results (Iwano et al., 2004). The cytosolic $\left[\mathrm{Ca}^{2+}\right]$ increased at different time points: in pollen grain, after hydration until germination, and in the stigmatic cells after pollen grain adhesion and hydration, after pollen tube emergence from the pollen grain and after the pollen tube penetrated the stigmatic cell wall. This shows that $\mathrm{Ca}^{2+}$ acts most probably as an intracellular signaling factor during pollen grain and stigmatic cells interaction, for pollen tube formation and initial polarized tip growth. Curiously, recent findings about the enigmatic mode of action of AGPs, suggested they might act as $\mathrm{Ca}^{2+}$ capacitors (Lamport and Várnai, 2012; Lamport et al., 2014). If so, AGPs may be important molecules in this first steps of interaction, being responsible for the release of periplasmic $\mathrm{Ca}^{2+}$ to be integrated in these cytosolic $\mathrm{Ca}^{2+}$ oscilations.

By using immunolocalization studies Losada and Herrero (2012) discovered that the developmental pattern of AGP expression in stigmatic tissues of the apple flower were correlated with the stigma receptivity stages, supporting the above hypothesis of AGPs involvement in this important step of plant reproduction. Later, the same authors (Losada and Herrero, 2014) also showed that, opposed to what happens in Arabidopsis, in Mallus domestica AGPs are detected in the stigma but not in the transmitting tract, and this relates to the fact that pollen tubes grow slower in the stigmatic tissues and faster in the transmitting tract tissues.

Finally, after initiating the growth through the stigmatic cell walls, the pollen tube will start a long journey that will lead it into the embryo sac.

\section{POLLEN TUBE GROWTH ON THE SUPERHIGHWAY - COURTSHIP}

Once germinated and the pollen tube formed, a new phase in the pollen tube-pistil interaction story starts. In Arabidopsis pollen tubes penetrate stigmatic cells and grow directly through the cell wall and into the cytosol, forcing their way through the basal wall region and into the transmitting tract tissue (Hiscock and Allen, 2008). The pollen tube has an intercellular growth through the stylar cells until reaching the embryo sac (Hulskamp et al., 1995; Johnson and Preuss, 2002; Lord and Russell, 2002).
In the initial sporophytic phase of attraction, the pollen tube grows through the transmitting tract, a specialized tissue extremely rich in glycoproteins, polysaccharides, and glycolipids, which are thought to facilitate and nourish the pollen tube development (Faure et al., 2002; Crawford and Yanofsky, 2008).

In Nicotiana tabacum AGPs called TTS (Transmitting TissueSpecific) are abundant in the extracellular matrix of the transmitting tract, being related to pollen tube guidance into the ovules. These glycoproteins stimulate pollen tube growth in vitro, are able to attract pollen tubes in semi-in vivo assays, and are essential for optimal pollen tube growth in vivo. The action of pollen tube hydrolases on the carbohydrate component of these glycoproteins conduces to the establishement of an increasing gradient from the top to the bottom of Nicotiana styles, which is suggested to have a chemotropic effect on growing pollen tubes. TTS are proposed to function as a nutrient source and act as adhesion molecules for pollen tube growth (Cheung et al., 1995; Wu et al., 1995, 2001). Arabidopsis $n t t$ (no transmitting tract) mutants, with abnormal transmitting tract development, show severe defects in pollen tube growth, which is slower, leading to a reduced fertilization rate (Crawford et al., 2007). NTT encodes a $\mathrm{C} 2 \mathrm{H} 2 / \mathrm{C} 2 \mathrm{HC}$ zinc finger transcription factor involved in the control of extracellular matrix production, being essential for PCD in transmitting tract tissues after pollination, essential for pollen tube growth (Crawford et al., 2007). Besides, the ntt mutants presents a reduced staining for acidic polysaccharides, which Crawford et al. (2007) speculated to be related to a reduction in AGPs content, since these are acidic glycoproteins and a main component of the transmitting tract. In fact, specific AGPs such as AGP1, AGP4 (JAGGER), and AGP19, were shown to be abundantly expressed in this tissue (Yang et al., 2007; Pereira et al., 2014, 2016b). JAGGER was identified as an AGP highly expressed in the transmitting tract tissues (Pereira et al., 2016b) although its mutant analysis did not reveal any phenotype related to this expression pattern. It will be of most interest to check whether transmitting tract AGPs expression is somehow under the control of the NTT transcription factor, and other specific transmitting tract transcription factors, such as the HECATE1, HECATE2, and HECATE3 (Gremski et al., 2007).

Several AGPs are already identified along the whole pollen tube growth pathway (Figure 2). AGP1, 4, 12, and 15 were identified in papilla cells of the stigma and in the style, and may be responsible for the functions proposed for AGPs in the above section. AGP1 and AGP4 in transmitting tract cells of the style and in the ovary, while AGP1, AGP4, AGP9, AGP12, and AGP15 are expressed in ovules, which develop into seeds after fertilization (Pereira et al., 2014). The genetic expression and function of another AGP, AGP19, was characterized by Yang et al. (2007) and the GUS promoter analysis showed its expression in the style, ovary walls, transmitting tract and siliques, with no expression in anthers, indicating its specificity to the female tissues. Its knockout plants revealed reduced flower production and fewer and shorter siliques than wild-type plants, revealing the importance of this specific AGP in reproduction. All these studies point out the importance of AGPs along the reproductive process.

Other important players have been shown to be involved in the molecular interactions between the pollen tube and 


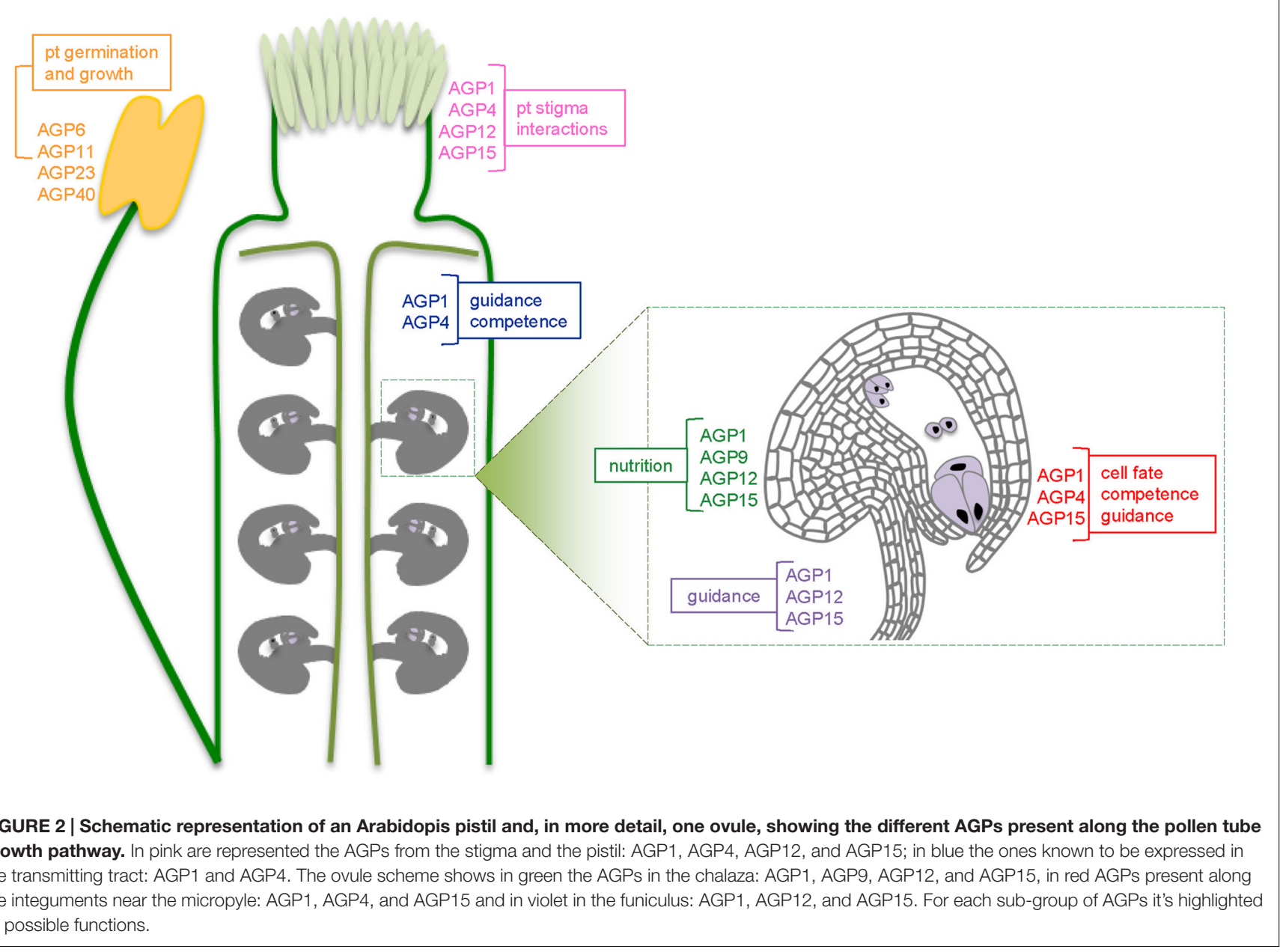

the transmitting tract tissues. POLLEN ON PISTIL 2 (POP2) encoding a $\gamma$-aminobutyric acid (GABA) transaminase, is involved in degrading GABA, establishing an increasing [GABA] gradient from the stigma until the ovule integuments, similar to what happens with the TTS glycoproteins (Palanivelu et al., 2003). This gradient is also believed to sustain pollen tube guidance though the transmitting tract. A plant lipid transfer protein, SCA (stylar cysteine-rich adhesion), was shown to be secreted from the transmitting tract epidermis and involved in adhesion-mediated pollen tube guidance by the formation of an adhesive pectin matrix that guides the pollen tubes toward the ovules (Mollet et al., 2000; Park et al., 2000). Interestingly, one recently identified AGP, AGP57C (Showalter et al., 2010) was shown to be the core of a proteoglycan with covalently attached arabinogalactan, arabinoxylan, and pectin domains. This highly glycosylated proteoglycan was named ARABINOXYLAN PECTIN ARABINOGALACTAN PROTEIN1 (APAP1) by Tan et al. (2013). This AGP was shown to cross-link in cell walls with pectin and hemicellulose polysaccharides, allowing the formation of a continuous network between polysaccharides and wall structural proteins. This APAP1 may be involved in the formation of the adhesive pectin matrix proposed earlier for pollen tube guidance mediation (Mollet et al., 2000; Park et al., 2000).

In L. longiflorum a chemotropic compound from the stigma was identified as a chemocyanin. This small plantacyanin cell wall protein, appears to regulate lily pollen tube directional growth (Kim et al., 2003). In A. thaliana, a unique plantacyanin gene was found with $51.9 \%$ identity and $86.8 \%$ similarity to lily chemocyanin at the amino acid level. Dong et al. (2005) hypothesized that this plantacyanin may act in the reproductive process, since it is part of the extracellular matrix of the transmitting tract and its overexpression in the pistil led to the disruption of pollen tube growth from the stigma to the style. Later, Mashiguchi et al. (2009) identified a family of early nodulin-like proteins (ENODLs) as chimeric AGPs, related to the phytocyanin family. In this study, the characterization of single ENODLs mutants did not reveal any novel biological functions for them, despite their high expression in floral organs. This ENODLs share AGPs characteristics, binding to the $\beta$-Yariv reagent, a synthetic chemical that specifically bind to AGPs. But also share a structure similarity with phytocyanins, although they lack the specific sub-unit that binds copper, like most phytocyanins. Showalter et al. (2010) have also identified this ENODLs as chimeric AGPs. But only now, their functions started 
to be unraveled by Hou et al. (2016), as it will be described in the next section.

More recently, the amino acid $D$-serine was shown to play a role in pollen tube guidance through the transmitting tract by mediating $\mathrm{Ca}^{2+}$-influx into the pollen tube cytoplasm involving glutamate receptor-like channels (Michard et al., 2011). Once again, such as in stigma-pollen grain interactions, AGPs may serve as $\mathrm{Ca}^{2+}$ capacitors (Lamport and Várnai, 2012; Lamport et al., 2014), making $\mathrm{Ca}^{2+}$ available for its influx mediated by $D$-serine.

Still, it is not clear how all these transmitting tract constituents interact with the growing pollen tube promoting or/and supporting its growth. It is clear that there must be a tightly controlled activation and/or inactivation of specific receptors in pollen tubes and transmitting tract cells as well as the production of ligands by the transmitting tract to coordinate the pollen tube growth toward the embryo sac. Several microarray-based approaches have been used to identify novel intervenients in pollen tube-sporophyte interaction mechanisms (Tung et al., 2005; Qin et al., 2009; Boavida et al., 2011). Interestingly, all these studies show enrichment in secreted proteins and cell-wallrelated proteins potentially involved in extracellular signaling and extracellular matrix modifications. Besides the importance of these interactions for the pollen tube growth along the pistil tissues, the different components present in these tissues point out for a contact-mediated competence that must be conferred by the stigma and style to the pollen tube in order for it to become receptive to ovule signals (Palanivelu and Preuss, 2006).

The presence of AGPs along this pollen tube pathway into the ovule embryo sac has been documented in numerous and phylogenetically diverse plant species [Gleeson and Clarke, 1980; Hoggart and Clarke, 1984; Sedgley et al., 1985; Webb and Williams, 1988; Jauh and Lord, 1996; Coimbra and Salema, 1997; Lennon et al., 1998; Cheung et al., 2000; Wu et al., 2000; Coimbra and Duarte, 2003; Peng et al., 2005; Coimbra et al., 2007; Losada and Herrero, 2012, 2014; Costa et al., 2013; Suárez et al., 2013 (for a more detailed description see Pereira et al., 2015)].

A new study on pollen tube guidance discovered AMOR, a sporophytic ovular factor that induces pollen tube competency in Torenia to respond to female signals (Mizukami et al., 2016). Mizukami et al. (2016) discovered a non-proteinaceous competence factor, acting in a non-species-preferential manner. AMOR activity was identified as a methyl-glucuronosyl arabinogalactan (AG) polysaccharide. A chemically synthesized disaccharide, the $\beta$-epimer of methyl-glucuronosyl galactose (4-Me-GlcA- $\beta-(1 / 6)-G a l$ or $4 \mathrm{Me}-\mathrm{GlcA}-\mathrm{Gal})$, showed full AMOR activity, while the disaccharide lacking a methyl group was completely inactive. The disaccharide 4Me-GlcA-Gal occurs exposed on AGPs side chains (Pereira et al., 2015). Arabinogalactan polysaccharides are added to proteins using $\mathrm{O}$-glycosylation onto hydroxyproline residues in the AGP backbone - the addition of this polysaccharides results in a glycoprotein with a mainly carbohydrate interactive molecular surface. In Torenia, the arabinogalactan AMOR enables pollen tubes to respond to female gametophyte-derived attraction signals. Notably, AGPs are very abundant along the pollen tube pathway and occur in the transmitting tract, placenta, funiculus and the micropylar opening of the ovule in Arabidopsis and many other species as mentioned above (Cheung et al., 1995; Coimbra et al., 2007; Pereira et al., 2014). These AGPs are most probably the source of this AMOR glycan. What remains to be determined is which specific AGP is responsible for their production? How are they "cleaved" out of the AGP and released into the extracellular medium? Which enzymes act in this possible step? Besides all these unanswered questions, the most important now is to know what happens in the model species A. thaliana, because, as Dresselhaus and Coimbra (2016) reminded us "pollen tubes, for example, appear almost competent without ovules and thus may not need priming by AMOR." However, in Arabidopsis it is known that pollen tubes grown in semi-in vivo assays, as long as they pass through a cut style, they become competent enough to reach the ovules and enter it (Palanivelu and Preuss, 2006). And here, another question arises: since these tissues (stigma, and style transmitting tract) are extremely rich in AGPs, can it be that they have already become competent because they were in contact with enough AMOR glycans? Or this step does not involve AGPs, but other molecules? This implies to better understand AGPs mode of action, which components of this complex hydroxyproline-rich proteins are essential for the pollen tubes to acquire competence, or even to act in other functions, such as nutrition or guidance.

\section{FUNICULAR AND MICROPYLAR GROWTH - SEX LAWS}

Contrarily to the pollen tube guidance phase described above, completely dependent on signals from the sporophyte, the funicular and micropylar growth of the pollen tube is dependent on cues delivered, not only by the sporophytic tissues, but also by the female gametophyte. The Arabidopsis mutants magatama (maal and maa3, the latter encoding a helicase) show an abnormal female gametophyte development with pollen tubes being targeted to the micropylar region, but not entering the synergids (Shimizu and Okada, 2000; Shimizu et al., 2008). Also in Arabidopsis, two predicted $\mathrm{K}^{+}$transporters: CHX21 and CHX23 present in pollen tubes, are essential for pollen tube guidance at this stage. $\operatorname{ch} \times 21$ and $\operatorname{ch} \times 23$ pollen tubes grow normally through the transmitting tract but fail to turn in the direction of the ovule and do not grow along the funiculus. The perception of some ovule signals that are critical to shifting the axis of pollen tube polarity and directing its growth toward the ovule most probably fail in these mutants (Lu et al., 2011). Mitogen-activated protein kinases MPK3 and MPK4 from pollen were additionally shown to be essential for pollen tube guidance during the funicular guidance phase, although the micropylar guidance was not affected (Guan et al., 2014). A most recent study revealed that phytosulfokine (PSK) is essential to guide the pollen tube from the transmitting tract to the embryo sac. PSK is perceived by receptor kinases and requires sulfation by a tyrosylprotein sulfotransferase (TPST) to be active. pskr1-3 pskr21 and tpst siliques present a high level of unfertilized ovules and loss of funicular guidance, suggesting the importance of PSK for funicular guidance (Stührwohldt et al., 2015). Curiously, 
PSKR1 was recently shown to be involved in plant defense to pathogens as well as PSK (Mosher and Kemmerling, 2013). The MPK3/MPK6 signaling pathway and the PSK signaling may link common signaling networks in plant stress response and pollenpistil interactions. AGPs have been identified in the funiculus of Arabidopsis plants, such as AGP1, AGP12, and AGP15 (Pereira et al., 2014). These glycoproteins may play important signaling roles along this step, where pollen tubes turn from the transmitting tract to grow along the funiculus. Clearly, pollen tubes require a multiplicity of signaling pathways in order to perceive and respond to ovule signaling and determine its growth direction.

Considerable progress has been made in the last years in order to better understand what controls the last phase of pollen tube guidance, the micropylar guidance phase. When pollen tubes arrive at the micropylar region they must grow through this opening between the integuments of the ovules to reach the filiform apparatus, which are invaginations from the synergids' cell wall that greatly increase their extracellular contact area, as typical for active secreting cells (Huang and Russell, 1992). In Torenia fournieri, a species with a naked embryo sac, it was shown that the synergids are the female gametophyte cells responsible for the gametophytic guidance phase. Laser ablation studies revealed that both synergids are essential for pollen tube guidance, but a single synergid is also capable of attracting pollen tubes into the embryo sac (Higashiyama et al., 1998, 2001). Moreover, in Arabidopsis, the importance of the synergids as the source of guiding molecules in this phase was shown, by studying a transcription factor mutant, myb98. In this mutant the ovule develops normally, excepot for the synergids filiform apparatus, which does not develop normally, impairing pollen tube guidance at this step (Kasahara et al., 2005; Punwani and Drews, 2008). So, the synergid cells are the main source for chemo-attractants necessary for micropylar pollen tube guidance.

So far, molecular attractants produced by the synergid cells were identified in three different species. In T. fournieri a group of defensine like polypeptides (DEFL) was identified as pollen tube attractants produced by the synergids and secreted to the filiform apparatus' surface, the LUREs (Okuda et al., 2009). A DEFL subgroup CRP810/AtLURE1, was also identified in Arabidopsis, revealing to be essential for micropylar pollen tube guidance (Takeuchi and Higashiyama, 2012). In Zea mays, the EGG APPARATUS1 (ZmEA1), a small hydrophobic precursor protein of 94 aminoacids, is present not only in the synergids, but also in the egg cell, in the filiform apparatus and in the micropylar nucellus, and it is required for micropylar pollen tube guidance (Márton et al., 2005, 2012). The synergids are not the only cells regulating pollen tube guidance in Arabidopsis, CENTRAL CELL GUIDANCE (CCG) is expressed in the nucleus of the central cell and might function as a transcriptional regulator mediating pollen tube guidance, since pollen tubes fail to target the micropyle of mutant ovules (Chen et al., 2007). Furthermore, the egg cell expressed GEX3 protein was shown to play a role in ovular guidance of the pollen tube (Alandete-Saez et al., 2008).

On the male side two receptor-like kinases (RLKs) were shown to impair micropylar pollen tube guidance, LOST IN POLLEN TUBE GUIDANCE1 (LIP1) and 2 (LIP2). They are both localized in the pollen tube membrane and are involved in the AtLURE1-dependent guidance mechanism (Liu et al., 2013) although more evidences are necessary to prove that LIP1 and LIP2 interact with AtLUREs. Recently, a receptor that recognizes AtLURE1 was identified in Arabidopsis, a heteromer MDIS1-MIK, composed by two pairs of closely related RLKs: Male Discoverer 1 and 2 (MDIS1 and MDIS2) and MDIS1interacting RLK1 and 2 (MIK1 and MIK2) (Wang et al., 2016). All these molecules may act together as essential components of the receptor complex of pollen tube guidance, although the way in which this happens remains to be uncovered. Simultaneously, Takeuchi and Higashiyama (2016) discovered another set of pollen-specific RLK, PRKs, responsible for the sensing of AtLURE1 by the pollen tube. At the end, we have so many receptors, and only one attractant molecule in Arabidopsis? According to Higashiyama and Hamamura (2008) it is still unclear if there is only one attractant molecule produced by the synergids to guide the pollen tubes into the embryo sac or if several molecules are working redundantly or even together to control such an important step in plant reproduction. It is more likely that several molecules involved in an intricate signaling pathway are acting in this micropylar guidance phase, since, until today, there is no known mutant where a total blockage of pollen tube growth into the embryo sac is observed.

Arabinogalactan proteins are also expressed in ovule tissues and in the synergids, and have been suggested to act like signaling molecules or attractants for pollen tube guidance since they were detected by immunolocalization in ovules and synergid filiform apparatus of several species (Coimbra and Salema, 1997; Coimbra and Duarte, 2003; Coimbra et al., 2007). The most recent studies in Arabidopsis revealed the presence of specific AGPs in these tissues (Pereira et al., 2014), making it easier to further analyze their specific functions in the ovules. The presence of AGPs throughout different plant species is quite striking, even in the cork tree Quercus suber, recent studies, using immunolocalization as a detection method, revealed the specific presence of AGPs in the synergids and their filiform apparatus (Lopes et al., 2016).

\section{POLLEN TUBE BURST, SPERM CELL RELEASE, AND POLYTUBEY BLOCKAGE: ONE LIFE STAND}

Once in the ovule micropyle the pollen tube must enter the embryo sac through one of the synergids, arrest growth and burst inside it, releasing the two sperm cells. It was shown that the pollen tube does not enter directly into the synergids through the filiform apparatus but rather grows along this structure entering the embryo sac in a region with less cell wall invaginations (Leshem et al., 2013). In the recent years, the molecular interactions involved in pollen tube reception by the synergids as well as between the sperm cells and the female gametes have been thoroughly studied shedding some light into all these mechanisms (reviewed in Bleckmann et al., 2014). Although there is a long way to go until we comprehend 
all the mechanisms regulating such an important process for seed formation.

One of the first proteins to be related to pollen tube reception by the synergids was FERONIA/SIRÉNE (FER/SRN), a receptor like serine/threonine kinase that localizes to the synergids filiform apparatus (Huck et al., 2003; Rotman et al., 2003; Escobar-Restrepo et al., 2007). fer/srn pollen tubes fail to arrest growth, continue growing and do not release the sperm cells. This showed the active involvement of FER/SRN in mediating the signaling pathway responsible for pollen tubesynergid interaction. FER, as a Catharanthus roseus RLK1like kinase (CrRLK1Ls) possesses a malectin-like extracellular domain, thus, its ligand could be a carbohydrate or glycoprotein from the cell wall (Lindner et al., 2012a). The search for more candidate molecules involved in this step identified LORELEI (LRE) as a glycosylphosphatidylinositol (GPI)-anchored protein, predominantly expressed in the synergid cells. lre pollen tubes present a similar phenotype to that of fer/srn, where the pollen tube enters the embryo sac but fails to arrest and release the sperm cells (Capron et al., 2008). LRE is localized in the plasma membrane, therefore being a perfect candidate to participate in pollen tube-synergid interactions (Tsukamoto et al., 2010). Recently, Liu et al. (2016) have proved that LRE and FERONIA jointly function in pollen tube reception at the interface of the synergid cell and pollen tube. Through an elegant study, it was shown that LRE has two independent functions. Pollen tubes ectopically expressing LRE rescue lre mutants, being essential for this step of reproduction. This complements a study showing LRE function as chaperoning FER localization in the filiform apparatus (Li et al., 2015). Liu et al. (2016) also revealed an important finding about LRE; that its GPI anchor is not entirely essential for LRE function. It will be extremely important to check if this also applies to other GPI-anchored proteins, such as AGPs or ENODLs. This may determine if these glycoproteins are acting attached to the plasma membrane or, if they are released by specific enzymes, to interact with other molecules located away from them. Another gene identified whose loss-of-function resemble the fer phenotype is NORTIA (NTA), which encodes the MILDEW RESISTANCE LOCUS O 7 (MLO7) gene (Kessler et al., 2010). NTA localizes to cellular uncharacterized compartments, and becomes re-localized to the plasma membrane upon pollen tube arrival, in a FER-dependent manner, connecting FER to NTA in the same signaling network (Kessler et al., 2010). NTA contains a calmodulin-binding domain in its cytoplasmic C-terminus, possibly allowing synergid cell perception of $\mathrm{Ca}^{2+}$ oscillations during pollen tube reception (Iwano et al., 2012). Both lre/lre and nta/nta have a similar phenotype to fer but not fully penetrant like in the later, suggesting that they are important for pollen tube-synergid interaction but are probably acting redundantly with other unknown factor. abstinence by mutual consent, amc, also has a phenotype similar to fer, but this mutant is self-sterile, that is, the phenotype is observed only when both the pollen tube and the FG carry the amc allele (Boisson-Dernier et al., 2008). AMC encodes a peroxine involved in protein import in peroxisomes, which could be important for the production of small signaling molecule such as ROS or NO, being possibly involved in pollen tube-synergid signaling.
TURAN (TUN), encoding an UDP-glycosyltransferase protein was also identified as a possible molecule involved in pollen tube reception, since its mutant as a fer-like pollen tube overgrowth phenotype (Lindner et al., 2012b). VERDANDI (VDD) is a transcription factor belonging to the REproductive Meristem (REM) family, and $v d d$ shows defects in antipodal and synergid cell identity resulting in the absence of pollen tube burst so growth continues after targeting the synergid cells. Differently from the mutants described above, the overgrowth phenotype was not observed in $v d d$. VDD may act downstream of these cell surface signaling components (Matias-Hernandez et al., 2010). Recently, VDD and VALKYRIE (VAL), also a member of the REM family, were shown to act as a complex regulating the death of the receptive synergid cell, and the death (by bursting) of the pollen tube after growth arrest (Mendes et al., 2016).

Not so much is known about the male signaling components involved in pollen tube-synergid interactions. So far, ANXUR1 and 2 (ANX1 and ANX2) are the main components identified as pollen intervenients, they are closely related homologs of FER (Boisson-Dernier et al., 2009). The two RLKs are localized on the pollen tube tip plasma membrane and redundantly control the timing of pollen tube discharge. Their overexpression inhibits growth by over-activating exocytosis and over-accumulation of secreted cell wall material (Boisson-Dernier et al., 2013). Given this, the authors suggested that ANX inhibits pollen tube rupture and sperm discharge at the tip of growing pollen tubes constitutively, allowing pollen tube growth within maternal tissues, maintaining their cell wall integrity, until they reach the FG. Once at the FG, the female FER-dependent signaling cascade is activated to mediate pollen tube reception and fertilization, while male ANX-dependent signaling is deactivated, enabling the pollen tube to rupture and deliver its sperm cells (BoissonDernier et al., 2009; Miyazaki et al., 2009). Three pollen expressed transcription factors MYB97, MYB101, and MYB120, were reported to control the expression of genes whose encoding proteins play essential roles in pollen tube-synergid interactions (Liang et al., 2013). The single mutants did not reveal any phenotype, only the triple myb97 myb101 myb120 pollen tubes revealed uncontrolled growth and failed to discharge sperm cells after entering the synergids. These transcription factors are critical for the pollen tube to exchange signals with the synergids (Liang et al., 2013).

Very recently, Hou et al. (2016) described a small group of ENODLs, EN 11 - 15, as essential for pollen tube reception in Arabidopsis. These glycoproteins, described in the section above, are considered to be chimeric AGPs. They are expressed in the ovules, and at least two of them, EN14 and EN15, are enriched in the synergid filiform apparatus. The quintuple mutant revealed severe pollen tube defect during its entrance into the embryo sac. In this mutant the pollen tube enters the embryo sac but continues to grow and does not burst, similar to what happens in fer. Actually, the authors have proved that at least EN15 interacts with FER, suggesting its involvement in the signaling pathway activation.

Iwano et al. (2012) pointed out a possible role for the secondary messenger $\mathrm{Ca}^{2+}$ in regulating sperm cell delivery and fertilization. Cytosolic $\left[\mathrm{Ca}^{2+}\right]$ was shown to be essential for the 
control of PCD in both pollen tube and the receptive synergid and for sperm cell fusion with female gametes. Two different studies (Denninger et al., 2014; Ngo et al., 2014) showed that the pollen tube contact with the receptive synergid, mediated by FER and LRE, initiates oscillations in synergid cytosolic $\left[\mathrm{Ca}^{2+}\right]$ signatures. These oscillations culminate in a change from $\left[\mathrm{Ca}^{2+}\right]$ oscillations to a sustained global $\left[\mathrm{Ca}^{2+}\right]$ flood in the receptive synergid, until the moment the pollen tube bursts leading to PCD of the receptive synergid, and pollen tube own PCD. NTA is proposed to modulate the intensity of the synergid $\left[\mathrm{Ca}^{2+}\right]$ signatures in the synergids through its calmodulin binding site (Ngo et al., 2014). Ngo et al. (2014) proposed that the persistent synergid either retains its $\left[\mathrm{Ca}^{2+}\right]$ signature, being responsible for repelling additional pollen tubes after successful double fertilization or reprograms its $\left[\mathrm{Ca}^{2+}\right]$ signature to that of the receptive synergid upon the arrival of new pollen tubes for rescuing a failed fertilization event. Nevertheless, the signaling events responsible for PCD in the synergid cell are not understood yet. These $\mathrm{Ca}^{2+}$ oscillations may, as described in the above sections, be also regulated by AGPs acting as $\mathrm{Ca}^{2+}$ capacitors, given that they are abundant in pollen tubes and ovules.

In Arabidopsis, receptive synergid degeneration occurs after pollen tube arrival, but before pollen tube discharge (SandaklieNikolova et al., 2007) suggesting a pollen tube derived signal to initiate synergid cell degeneration. About the persisting synergid PCD little information is available. According to Schneitz et al. (1995), the persistent synergid disappears during the second and third endosperm nuclear division.

Following pollen tube entrance into the embryo sac through the receptive synergid there is a rapid transport of the sperm cells by pollen tube discharge to the chalazal pole of the receptive synergid. Sperm cells adhere to the surface of the female gametes with no preferential order regarding their position in the male germ unit. After this, sperm cells remain immobile for a fairly long period, approximately $7.4 \mathrm{~min}$, in the boundary between the egg and the central cell (Hamamura et al., 2011). Afterward, the membranes of both gametophytes fuse (plasmogamy) almost simultaneously, and the two sperm cell nuclei resumed their movement inside each female gamete toward their nuclei (Hamamura et al., 2011). During sperm cell fusion with the female gametes three central players have been identified so far: GAMETE EXPRESSED 2 (GEX2) (Mori et al., 2014); GENERATIVE CELL SPECIFIC 1/HAPLESS 2 (GCS1/HAP2) (Mori et al., 2005; von Besser et al., 2006) and the EGG CELL 1 (EC1) family (Sprunck et al., 2012). GEX2 encodes a sperm expressed protein localized to its membrane, containing extracellular immunoglobulin-like domains, and is required for gamete fusion. In gex2 sperm cells there is a reduced adhesion to female gametes, likely causing cell fusion failure (Mori et al., 2014). GCS1/HAP2 is predicted to encode a protein with an $\mathrm{N}$-terminal secretion signal, a single transmembrane domain and a C-terminal histidine-rich domain expressed only in the haploid sperm. gcs1/hap2 sperm cells delivered to ovules fail to initiate fertilization, the released sperm cells remain at the fusion site with female gametes, and end up leading to the attraction of multiple pollen tubes (Mori et al., 2005; von Besser et al., 2006). EC1, small cysteine-rich protein, is predicted to activate sperm cell for gamete fusion (Sprunck et al., 2012). EC1 is stored in vesicles in the egg cell, and secreted to the apical region of the degenerative synergid cell conducting to relocalization of the fusogen GCS1/HAP2 to the cell surface of the sperm cell. Before fertilization GCS1/HAP2 is localized in the endomembrane system (Mori et al., 2005). After this, sperm cells are activated and ready to fuse with the female gametes, leading to double fertilization.

In order to prevent multiple fertilization events (polyspermy), that could lead to embryo lethality or malformation of the endosperm, and thus reproductive failure, plants evolved mechanisms to protect them from this risk.

Maruyama et al. (2013) showed that the successful fertilization of the egg and the central cell initiates a blockage mechanism mediated by the FIS-PRC2 (Fertilization Independent Seed Polycomb Repressive Complex 2) complex, to avoid the attraction of multiple pollen tubes (polytubey). By the same time it was also shown the involvement of ethylene in triggering the persistent synergid cell death in order to avoid polytubey, involving the transcription factors EIN2 and EIN3 (ethylene insensitive 1 and 2). With the death of the persisting synergid, production of pollen tube attractants stop, leading to the polytubey blockage (Völz et al., 2013). It is now known that the persistent synergid cell is eliminated by its fusion with the endosperm and elimination of its nuclear contents: synergid-endosperm fusion (Maruyama et al., 2015). The same study revealed that this fusion is dependent on FIS-PRC2 complex and ethylene signaling activation by the central cell and the egg cell, respectively. Recently, Motomura et al. (2016) discovered that synergid-endosperm fusion takes place even in Arabidopsis mutants defective in MULTICOPY SUPRESSOR OF IRA1 (MSI1), a subunit of the PRC2 complex. In this mutant endosperm develops without the occurrence of fertilization. It reveals that the central cell fertilization is triggering the SE fusion, although synergid nuclear disorganization seems not to occur. This last step of the process needs to be clarified. It remains to be known how the persistent synergid nucleus is recognized as a target for elimination.

JAGGER (AGP4), the first specific AGP from Arabidopsis to reveal a function in the fertilization process, is important to prevent polytubey (Pereira et al., 2016b). jagger mutants fail to undergo persistent synergid cell death, leading to the attraction of more than one pollen tube per embryo sac. In this study it was demonstrated that JAGGER from the ovule integuments is the one responsible for this phenotype. How JAGGER is involved in this complex mechanism is still unknown. JAGGER might be one of the cell death markers for the persistent synergid nucleus, destining it for elimination (Pereira et al., 2016a). AGPs have already been described as molecular markers during development (Coimbra et al., 2007; Tucker and Koltunow, 2014).

In conclusion, this last step of pollen tube growth including pollen tube burst, sperm cell discharge and fusion with the female gametes along with the polytubey blockage system involves a complex and intricate system of communication and signaling mechanisms between the pollen tube and the female sporophytic and gametophytic tissues, ensuring double fertilization and, therefore, reproductive success. 


\section{CONCLUSION AND OUTLOOK}

Considering AGP roles, either as signaling or nutrient molecules and their carbohydrate epitopes differential presence in space and time along male and female reproductive tissues, it is unquestionable to affirm that AGPs are basal component interactors along the crosstalk channel established between the germinating pollen tube and the female tissues, for a successful double fertilization.

Arabinogalactan proteins can work as major players in the different steps of interaction between the pollen grain, pollen tube and the pistil tissues as they might intervene in pollen grain recognition, adhesion and germination and pollen tube growth initiation. AGPs are also fully developed to function as guiding, support, and nutrient providing molecules for pollen tube growth through the transmitting tract or mucilage of hollow pistils, along the style and the ovary and they are present in the ovules and funiculus, possibly working as attracting molecules for this final stage of pollen tube micropylar guidance. AGP presence at the ovule entrance tissues reveals their involvement also in the control of multiple pollen tube blockage - as evidenced by JAGGER (Pereira et al., 2016b).

Despite the need to use modern molecular tools to identify specific AGPs along the pollen tube growth pathway, immunolocalization studies of these glycoproteins are still essential to continue studying them. Not only because they are used to detect them in different plant species, but also because the specific glycosylations of each AGP is still not known. The available antibodies for immunolocalization studies are the only ones that detect different glycosidic AGPs epitopes. Different labeling patterns with different antibodies specific for the AGPs' carbohydrate moiety may reflect differences in the types of glycosylations present at different cell types and developmental stages. Besides, the great diversity of carbohydrates decorating AGPs may implicate a broad range of affinity and specificity of these molecules for wide variety of plant developmental functions. On the other hand, we do not know if the differences in glycosylations are very noticeable. This is an exciting field of research, but it is also what makes it so difficult to study this family of proteins.

If AGPs might play so many roles in so many different tissues, these will be due to differences in their carbohydrate moieties? Different glycosylation machineries may be available in different tissues leading to different kinds of posttranslational modifications? This was, many years ago, suggested by Pennell et al. (1991), as the hypothesis that each cell or tissue type, somatic or reproductive, may have different glycosylation machineries.

\section{REFERENCES}

Acosta-García, G., and Vielle-Calzada, J.-P. (2004). A classical arabinogalactan protein is essential for the initiation of female gametogenesis in Arabidopsis. Plant Cell 16, 2614-2628. doi: 10.1105/tpc.104. 024588

Alandete-Saez, M., Ron, M., and McCormick, S. (2008). GEX3, expressed in the male gametophyte and in the egg cell of Arabidopsis thaliana, is essential for
Recent AGPs specific hydroxyproline- $O-\beta$-galactosyltransferases loss of function mutants, galt2, galt3, galt4, and galt5 (Basu et al., 2013, 2015a,b) and hptg1, hptg2, and hptg3 (OgawaOhnishi and Matsubayashi, 2015) revealed the importance of the carbohydrate moieties of AGPs for its function, as speculated before, making them strong candidates for mediation of cellcell communication. Besides, a different study suggest AGPs to act as calcium chelators (Lamport and Várnai, 2012). It will be interesting to discover if some specific AGPs expressed along the reproductive tissues are acting in this way, taking into account that many of the reproductive events are dependent on calcium oscillations (Iwano et al., 2004, 2012; Michard et al., 2011). The problem of considering AGPs acting as calcium capacitors, is that we would be considering all AGPs to act in the same way. Why would the plant produce such a big family of glycoproteins, expressed differentially along the diverse plants tissues? It can be that AGPs are playing all these different roles simultaneously, considering that the family is so huge, it is quite possible that some are acting as calcium capacitors, and others in other more specific functions, such as JAGGER or AGP18.

The increasing supporting information on the importance of the carbohydrate moiety of AGPs for its functions (Cheung et al., 1995; Wu et al., 2000; Mizukami et al., 2016) together with the hypothesis that AGPs, even if closely related at the amino acid level, might play unique and different functions in different processes (de Graaf et al., 2003; Yang et al., 2007; Pereira et al., 2014), are being fused with the huge amount of knowledge on AGPs distribution throughout sexual reproductive tissues in many species. This will thus deeply clarify AGPs functions and mode of action, sustaining the fair importance these molecules are having in sexual plant reproduction.

\section{AUTHOR CONTRIBUTIONS}

AP, AL and SC made substantial contributions to the conception and design of this review, participated in drafting and revising it critically and give final approval of this version to be submitted and any revised version.

\section{FUNDING}

The work described in this review was supported by the EU project 690946 - SexSeed - Sexual Plant reproduction - Seed Formation, funded by H2020-MSCA-RISE-2015.

micropylar pollen tube guidance and plays a role during early embryogenesis. Mol. Plant. 1, 586-598. doi: 10.1093/mp/ssn015

Amien, S., Kliwer, I., Marton, M. L., Debener, T., Geiger, D., Becker, D., et al. (2010). Defensin-like ZmES4 mediates pollen tube burst in maize via opening of the potassium channel KZM1. PLoS Biol. 8:e1000388. doi: 10.1371/journal. pbio. 1000388

Basu, D., Liang, Y., Liu, X., Himmeldirk, K., Faik, A., Kieliszewski, M., et al. (2013). Functional identification of a hydroxyproline-O galactosyltransferase specific 
for arabinogalactan protein biosynthesis in Arabidopsis. J. Biol. Chem. 288, 10132-10143. doi: 10.1074/jbc.M112.432609

Basu, D., Tian, L., Wang, W., Bobbs, S., Herock, H., Travers, A., et al. (2015a). A small multigene hydroxyproline-O-galactosyltransferase family functions in arabinogalactan-protein glycosylation, growth and development in Arabidopsis. BMC Plant Biol. 15:295. doi: 10.1186/s12870-0150670-7

Basu, D., Wang, W., Ma, S., DeBrosse, T., Poirier, E., Emch, K., et al. (2015b). Two hydroxyproline galactosyltransferases, GALT5 and GALT2, function in arabinogalactan-protein glycosylation, growth and development in Arabidopsis. PLoS ONE 10:e0125624. doi: 10.1371/journal.pone.0125624

Beale, K. M., and Johnson, M. A. (2013). Speed dating, rejection, and finding the perfect mate: advice from flowering plants. Curr. Opin. Plant Biol. 16, 590-597. doi: 10.1016/j.pbi.2013.08.005

Bircheneder, S., and Dresselhaus, T. (2016). Why cellular communication during plant reproduction is particularly mediated by CRP signalling. J. Exp. Bot. 67, 4849-4861. doi: 10.1093/jxb/erw271

Bleckmann, A., Alter, S., and Dresselhaus, T. (2014). The beginning of a seed: regulatory mechanisms of double fertilization. Front. Plant Sci. 11:452. doi: $10.3389 /$ fpls.2014.00452

Boavida, L. C., Borges, F., Becker, J. D., and Feijó, J. A. (2011). Whole genome analysis of gene expression reveals coordinated activation of signaling and metabolic pathways during pollen-pistil interactions in Arabidopsis. Plant Physiol. 155, 2066-2080. doi: 10.1104/pp.110.169813

Boisson-Dernier, A., Frietsch, S., Kim, T.-H., Dizon, M. B., and Schroeder, J. I. (2008). The peroxin loss-of-function mutation abstinence by mutual consent disrupts male-female gametophyte recognition. Curr. Biol. 18, 63-68. doi: 10. 1016/j.cub.2007.11.067

Boisson-Dernier, A., Lituiev, D. S., Nestorova, A., Franck, C. M., Thirugnanarajah, S., and Grossniklaus, U. (2013). ANXUR receptor-like kinases coordinate cell wall integrity with growth at the pollen tube tip via NADPH oxidases. PLoS Biol. 11:e1001719. doi: 10.1371/journal.pbio. 1001719

Boisson-Dernier, A., Roy, S., Kritsas, K., Grobei, M. A., Jaciubek, M., Schroeder, J. I., et al. (2009). Disruption of the pollen-expressed FERONIA homologs ANXUR1 and ANXUR2 triggers pollen tube discharge. Development 136, 3279-3288. doi: 10.1242/dev.040071

Borg, M., and Twell, D. (2010). Life after meiosis: patterning the angiosperm male gametophyte. Biochem. Soc. Trans. 38, 577-582. doi: 10.1042/ BST0380577

Borner, G. H. H., Lilley, K. S., Stevens, T. J., and Dupree, P. (2003). Identification of glycosylphosphatidylinositol-anchored proteins in Arabidopsis. A proteomic and genomic analysis. Plant Physiol. 132, 568-577.

Capron, A., Gourgues, M., Neiva, L. S., Faure, J. E., Berger, F., Pagnussat, G., et al. (2008). Maternal control of male- gamete delivery in Arabidopsis involves a putative GPI-anchored protein encoded by the LORELEI gene. Plant Cell 20, 3038-3049. doi: $10.1105 /$ tpc. 108.061713

Chapman, L. A., and Goring, D. R. (2010). Pollen-pistil interactions regulating successful fertilization in the Brassicaceae. J. Exp. Bot. 61, 1987-1999. doi: $10.1093 /$ jxb/erq021

Chapman, L. A., and Goring, D. R. (2011). Misregulation of phosphoinositides in Arabidopsis thaliana decreases pollen hydration and maternal fertility. Sex. Plant Reprod. 24, 319-326. doi: 10.1007/s00497-011-0172-1

Chen, Y.-H., Li, H.-J., Shi, D.-Q., Yuan, L., Liu, J., Sreenivasan, R., et al. (2007). The central cell plays a critical role in pollen tube guidance in Arabidopsis. Plant Cell 19, 3563-3577. doi: 10.1105/tpc.107.053967

Cheung, A. Y., Wang, H., and Wu, H. M. (1995). A floral transmitting tissuespecific glycoprotein attracts pollen tubes and stimulates their growth. Cell 82, 383-393. doi: 10.1016/0092-8674(95)90427-1

Cheung, A. Y., Wu, H. M., de Stilio, V., Glaven, R., Chen, C., Wong, E., et al. (2000). Pollen-pistil interactions in Nicotiana tabacum. Ann. Bot. 85(Suppl. A), 29-37. doi: 10.1006/anbo.1999.1016

Coimbra, S., Almeida, J., Junqueira, V., Costa, M. L., and Pereira, L. G. (2007). Arabinogalactan proteins as molecular markers in Arabidopsis thaliana sexual reproduction. J. Exp. Bot. 58, 4027-4035. doi: 10.1093/jxb/ erm259

Coimbra, S., and Duarte, C. (2003). Arabinogalactan proteins may facilitate the movement of pollen tubes from the stigma to the ovules in Actinidia deliciosa and Amaranthus hypochondriacus. Euphytica 133, 171-178. doi: 10.1023/A: 1025564920478

Coimbra, S., and Salema, R. (1997). Immunolocalization of arabinogalactan proteins in Amaranthus hypochondriacus L. ovules. Protoplasma 199, 75-82. doi: 10.1007/BF02539808

Costa, M., Pereira, A. M., Rudall, P. J., and Coimbra, S. (2013). Immunolocalization of arabinogalactan proteins (AGPs) in reproductive structures of an earlydivergent angiosperm, Trithuria (Hydatellaceae). Ann. Bot. 111, 183-190. doi: $10.1093 / \mathrm{aob} / \mathrm{mcs} 256$

Crawford, B., Ditta, G., and Yanofsky, M. (2007). The ntransmitting tract gene is required for transmitting- tract development in carpels of Arabidopsis thaliana. Curr. Biol. 17, 1101-1108. doi: 10.1016/j.cub.2007.05.079

Crawford, B. C., and Yanofsky, M. F. (2008). The formation and function of the female reproductive tract in flowering plants. Curr. Biol. 18, R972-R978. doi: 10.1016/j.cub.2008.08.010

Dardelle, F., Lehner, A., Ramdani, Y., Bardor, M., Lerouge, P., Driouich, A., et al. (2010). Biochemical and immunocytological characterizations of Arabidopsis pollen tube cell wall. Plant Physiol. 153, 1563-1576. doi: 10.1104/pp.110.158881

de Graaf, B. H. J., Knuiman, B. A., Derksen, J., and Mariani, C. (2003). Characterization and localization of the transmittingtissue-specific PELPIII proteins of Nicotiana tabacum. J. Exp. Bot. 54, 55-63. doi: 10.1093/jxb/erg002

Demesa-Arévalo, E., and Vielle-Calzada, J.-P. (2013). The classical arabinogalactan protein AGP18 mediates megaspore selection in Arabidopsis. Plant Cell. 25, 1274-1287. doi: 10.1105/tpc.112.106237

Denninger, P., Bleckmann, A., Lausser, A., Vogler, F., Ott, T., Ehrhardt, D., et al. (2014). Male-female communication triggers calcium signatures during fertilization in Arabidopsis. Nat Commun. 5:4645. doi: 10.1038/ncomms5645

Dong, J., Kim, S. T., and Lord, E. M. (2005). Plantacyanin plays a role in reproduction in Arabidopsis. Plant Physiol. 138, 778-789. doi: 10.1104/pp.105. 063388

Doucet, J., Lee, H. K., and Goring, D. R. (2016). Pollen acceptance or rejection: a tale of two pathways. Trends Plant Sci. 21, 1058-1067. doi: 10.1016/j.tplants. 2016.09.004

Dresselhaus, T., and Coimbra, S. (2016). Plant reproduction: AMOR enables males to respond to female signals. Curr. Biol. 26, R321-R323. doi: 10.1016/j.cub.2016. 03.019

Dresselhaus, T., and Franklin-Tong, N. (2013). Male-female crosstalk during pollen germination, tube growth and guidance, and double fertilization. Mol. Plant. 6, 1018-1036. doi: 10.1093/mp/sst061

Dresselhaus, T., Sprunck, S., and Wessel, G. M. (2016). Fertilization mechanisms in flowering plants. Curr. Biol. 26, R125-R139. doi: 10.1016/j.cub.2015.12.032

Drews, G. N., Lee, D., and Christensen, C. A. (1998). Genetic analysis of the female gametophyte development and function. Plant Cell 10, 5-17. doi: 10.1105/tpc. 10.1 .5

Escobar-Restrepo, J. M., Huck, N., Kessler, S., Gagliardini, V., Gheyselinck, J., Yang, W. C., et al. (2007). The FERONIA receptor-like kinase mediates malefemale interactions during pollen tube reception. Science 317, 656-660. doi: $10.1126 /$ science. 1143562

Faure, J. E., Rotman, N., Fortune, P., and Dumas, C. (2002). Fertilization in Arabidopsis thaliana wild type: developmental stages and time course. Plant $J$. 30, 481-488. doi: 10.1046/j.1365-313X.2002.01305.x

Gleeson, P. A., and Clarke, A. E. (1980). Arabinogalactans of sexual and somatic tissues of Gladiolus and Lilium. Phytochemistry 19, 1777-1782. doi: 10.1016/ S0031-9422(00)83812-1

Gremski, K., Ditta, G., and Yanofsky, M. F. (2007). The HECATE genes regulate female reproductive tract development in Arabidopsis thaliana. Development 134, 3593-3601. doi: 10.1242/dev.011510

Guan, Y., Lu, J., Xu, J., McClure, B., and Zhang, S. (2014). Two mitogen-activated protein kinases, MPK3 and MPK6, are required for funicular guidance of pollen tubes in Arabidopsis. Plant Physiol. 165, 528-533. doi: 10.1104/pp.113.231274

Hamamura, Y., Saito, C., Awai, C., Kurihara, D., Miyawaki, A., Nakagawa, T., et al. (2011). Live-cell imaging reveals the dynamics of two sperm cells during double fertilization in Arabidopsis thaliana. Curr. Biol. 21, 497-502. doi: 10.1016/j.cub. 2011.02.013

Hao, L., Liu, J., Zhong, S., Gu, H., and Qu, L. J. (2016). AtVPS41-mediated endocytic pathway is essential for pollen tube-stigma interaction in Arabidopsis. Proc. Natl. Acad. Sci. U.S.A. 113, 6307-6312. doi: 10.1073/pnas.16027 57113 
He, B., Xi, F., Zhang, X., Zhang, J., and Guo, W. (2007). Exo70 interacts with phospholipids and mediates the targeting of the exocyst to the plasma membrane. EMBO J. 26, 4053-4065. doi: 10.1038/sj.emboj.7601834

Higashiyama, T., and Hamamura, Y. (2008). Gametophytic pollen tube guidance. Sex. Plant Reprod. 21, 17-26. doi: 10.1007/s00497-007-0064-6

Higashiyama, T., Kuroiwa, H., Kawano, S., and Kuroiwa, T. (1998). Guidance in vitro of the pollen tube to the naked embryo sac of Torenia fournieri. Plant Cell 10, 2019-2032. doi: 10.2307/3870781

Higashiyama, T., and Takeuchi, H. (2015). The mechanism and key molecules involved in pollen tube guidance. Annu. Rev. Plant Biol. 66, 393-413. doi: 10.1146/annurev-arplant-043014-115635

Higashiyama, T., Yabe, S., Sasaki, N., and Nishimura, Y. (2001). Pollen tube attraction by the synergid cell. Science 293, 1480-1483. doi: 10.1126/science. 1062429

Hiscock, S. J., and Allen, A. M. (2008). Diverse cell signalling pathways regulate pollen-stigma interactions: the search for consensus. New Phytol. 179, 286-317. doi: $10.1111 / j .1469-8137.2008 .02457 . x$

Hoggart, R. M., and Clarke, A. E. (1984). Arabinogalactans are common components of Angiosperm styles. Phytochemistry 23, 1571-1573. doi: 10.1016/ S0031-9422(00)83441-X

Hou, Y., Guo, X., Cyprys, P., Zhang, Y., Bleckmann, A., Cai, L., et al. (2016). Maternal ENODLs are required for pollen tube reception in Arabidopsis. Curr. Biol. 26, 1-8. doi: 10.1016/j.cub.2016.06.053

Huang, B.-Q., and Russell, S. D. (1992). Female germ unit: organization, isolation, and function. Int. Rev. Cytol. 140, 233-292. doi: 10.1016/S0074-7696(08) 61099-2

Huck, N., Moore, J. M., Federer, M., and Grossniklaus, U. (2003). The Arabidopsis mutant feronia disrupts the female gametophytic control of pollen tube reception. Development 130, 2149-2159. doi: 10.1242/dev.00458

Hulskamp, M., Schneitz, K., and Pruitt, R. E. (1995). Genetic evidence for a longrange activity that directs pollen tube guidance in Arabidopsis. Plant Cell 7, 57-64. doi: 10.1105/tpc.7.1.57

Iwano, M., Ngo, Q. A., Entani, T., Shiba, H., Nagai, T., Miyawaki, A., et al. (2012). Cytoplasmic $\mathrm{Ca} 2+$ changes dynamically during the interaction of the pollen tube with synergid cells. Development 139, 4202-4209. doi: 10.1242/dev.081208

Iwano, M., Shiba, H., Miwa, T., Che, F. S., Takayama, S., Nagai, T., et al. (2004). Ca2+ dynamics in a pollen grain and papilla cell during pollination of Arabidopsis. Plant Physiol. 136, 3562-3571. doi: 10.1104/pp.104.046961

Jauh, G. Y., and Lord, E. M. (1996). Localization of pectins and arabinogalactanproteins in lily (Lilium longittorum L.) pollen tube and style, and their possible roles in pollination. Planta 199, 251-261. doi: 10.1007/BF00196566

Johnson, M. A., and Preuss, D. (2002). Plotting a course: multiple signals guide pollen tubes to their targets. Dev. Cell 2, 273-281. doi: 10.1016/S1534-5807(02) 00130-2

Kasahara, R. D., Portereiko, M. F., Sandaklie-Nikolova, L., Rabiger, D. S., and Drews, G. N. (2005). MYB98 is required for pollen tube guidance and synergid cell differentiation in Arabidopsis. Plant Cell 17, 2981-2992. doi: 10.1105/tpc. 105.034603

Kessler, S. A., Shimosato-Asano, H., Keinath, N. F., Wuest, S. E., Ingram, G., Panstruga, R., et al. (2010). Conserved molecular components for pollen tube reception and fungal invasion. Science 330, 968-971. doi: 10.1126/science. 1195211

Kim, S., Mollet, J.-C., Dong, J., Zhang, K., Park, S.-Y., and Lord, E. M. (2003). Chemocyanin, a small basic protein from the lily stigma, induces pollen tube chemotropism. Proc. Natl. Acad. Sci. U.S.A. 100, 16125-16130. doi: 10.1073/ pnas. 2533800100

Lamport, D. T. A., Varnai, P., and Seal, C. E. (2014). Back to the future with the AGP-Ca ${ }^{2+}$ flux capacitor. Ann. Bot. 114, 1069-1085. doi: 10.1093/aob/mcul61

Lamport, D. T., and Várnai, P. (2012). Periplasmic arabinogalactan glycoproteins act as a calcium capacitor that regulates plant growth and development. New Phytol. 197, 58-64. doi: 10.1111/nph.12005

Lennon, K. A., Roy, S., Hepler, P. K., and Lord, E. M. (1998). The structure of the transmitting tissue of Arabidopsis thaliana (L.) and the path of pollen tube growth. Sex. Plant Reprod. 11, 49-59. doi: 10.1007/s004970050120

Leshem, Y., Johnson, C., and Sundaresan, V. (2013). Pollen tube entry into the synergid cell of Arabidopsis is observed at a site distinct from the filiform apparatus. Plant Reprod. 26, 93-99. doi: 10.1007/s00497-013-0211-1
Li, C., Yeh, F. L., Cheung, A. Y., Duan, Q., Kita, D., Liu, M. C., et al. (2015). Glycosylphosphatidylinositol-anchored proteins as chaperones and coreceptors for FERONIA receptor kinase signaling in Arabidopsis. Elife 4:e06587. doi: 10.7554/eLife.06587

Li, L., and Sheen, J. (2016). Dynamic and diverse sugar signaling. Curr. Opin. Plant Biol. 33, 116-125. doi: 10.1016/j.pbi.2016.06.018

Liang, Y., Tan, Z.-M., Zhu, L., Niu, Q.-K., Zhou, J.-J., Li, M., et al. (2013). MYB97, MYB101 and MYB120 function as male factors that control pollen tube- synergid interaction in Arabidopsis thaliana fertilization. PLoS Genet. 9:e1003933. doi: 10.1371/journal.pgen.1003933

Lindner, H., Muller, L. M., Boisson-Dernier, A., and Grossniklaus, U. (2012a). CrRLK1L receptor- like kinases: not just another brick in the wall. Curr. Opin. Plant Biol. 15, 659-669. doi: 10.1016/j.pbi.2012.07.003

Lindner, H., Raissig, M. T., Sailer, C., Shimosato-Asano, H., Bruggmann, R., and Grossniklaus, U. (2012b). SNP-Ratio Mapping (SRM): identifying lethal alleles and mutations in complex genetic backgrounds by next-generation sequencing. Genetics 191, 1381-1386. doi: 10.1534/genetics.112.141341

Liu, J., Zhong, S., Guo, X., Hao, L., Wei, X., Huang, Q., et al. (2013). Membranebound RLCKs LIP1 and LIP2 are essential male factors controlling male-female attraction in Arabidopsis. Curr. Biol. 23, 993-998. doi: 10.1016/j.cub.2013.04. 043

Liu, J., Zuo, X., Yue, P., and Guo, W. (2007). Phosphatidylinositol 4,5-bisphosphate mediates the targeting of the exocyst to the plasma membrane for exocytosis in mammalian cells. Mol. Biol. Cell 18, 4483-4492. doi: 10.1091/mbc.E07-05-0461

Liu, X., Castro, C., Wang, Y., Noble, J., Ponvert, N., Bundy, M., et al. (2016). The role of LORELEI in pollen tube reception at the interface of the synergid cell and pollen tube requires the modified eight-cysteine motif and the receptor-like kinase FERONIA. Plant Cell 28, 1035-1052. doi: 10.1105/tpc.15. 00703

Lord, E. M., and Russell, S. D. (2002). The mechanisms of pollination and fertilization in plants. Annu. Rev. Cell Dev. Biol. 18, 81-105. doi: 10.1146/ annurev.cellbio.18.012502.083438

Lopes, A. L., Costa, M. L., Sobral, R., Costa, M. M., Amorim, M. I., and Coimbra, S. (2016). Arabinogalactan proteins and pectin distribution during female gametogenesis in Quercus suber L. Ann. Bot. 117, 949-961. doi: 10.1093/ $\mathrm{aob} / \mathrm{mcw} 019$

Losada, J. M., and Herrero, M. (2012). Arabinogalactan-protein secretion is associated with the acquisition of stigmatic receptivity in the apple flower. Ann. Bot. 110, 573-584. doi: 10.1093/aob/mcs116

Losada, J. M., and Herrero, M. (2014). Glycoprotein composition along the pistil of Malus $\mathrm{x}$ domestica and the modulation of pollen tube growth. BMC Plant Biol. 14:1. doi: 10.1186/1471-2229-14-1

Lu, Y., Chanroj, S., Zulkifli, L., Johnson, M. A., Uozumi, N., Cheung, A., et al. (2011). Pollen tubes lacking a pair of $\mathrm{K}+$ transporters fail to target ovules in Arabidopsis. Plant Cell 23, 81-93. doi: 10.1105/tpc.110.080499

Márton, M. L., Cordts, S., Broadhvest, J., and Dresselhaus, T. (2005). Micropylar pollen tube guidance by egg apparatus 1 of maize. Science 307, 573-576. doi: 10.1126/science.1104954

Márton, M. L., Fastner, A., Uebler, S., and Dresselhaus, T. (2012). Overcoming hybridization barriers by the secretion of the maize pollen tube attractant ZmEA1 from Arabidopsis ovules. Curr. Biol. 22, 1194-1198. doi: 10.1016/j.cub. 2012.04.061

Maruyama, D., Hamamura, Y., Takeuchi, H., Susaki, D., Nishimaki, M., Kurihara, D., et al. (2013). Independent control by each female gamete prevents the attraction of multiple pollen tubes. Dev. Cell 25, 317-323. doi: 10.1016/j. devcel.2013.03.013

Maruyama, D., Völz, R., Takeuchi, H., Mori, T., Igawa, T., Kurihara, D., et al. (2015). Rapid elimination of the persistent synergid through a cell fusion mechanism. Cell 161, 907-918. doi: 10.1016/j.cell.2015.03.018

Mashiguchi, K., Asami, T., and Suzuki, Y. (2009). Genome-wide identification, structure and expression studies, and mutant collection of 22 early nodulinlike protein genes in Arabidopsis. Biosci. Biotechnol. Biochem. 73, 2452-2459. doi: $10.1271 / \mathrm{bbb} .90407$

Matias-Hernandez, L., Battaglia, R., Galbiati, F., Rubes, M., Eichenberger, C., Grossniklaus, U., et al. (2010). VERDANDI is a direct target of the MADS domain ovule identity complex and affects embryo sac differentiation in Arabidopsis. Plant Cell 22, 1702-1715. doi: 10.1105/tpc.109.068627 
Mayfield, J. A., Fiebig, A., Johnstone, S. E., and Preuss, D. (2001). Gene families from the Arabidopsis thaliana pollen coat proteome. Science 292, 2482-2485. doi: $10.1126 /$ science. 1060972

Mayfield, J. A., and Preuss, D. (2000). Rapid initiation of Arabidopsis pollination requires the oleosin-domain protein GRP17. Nat. Cell Biol. 2, 128-130. doi: $10.1038 / 35000084$

McCormick, S. (2004). Control of male gametophyte development. Plant Cell 16, S142-S153. doi: 10.1105/tpc.016659

Mendes, M. A., Guerra, R. F., Castelnovo, B., Silva-Velazquez, Y., Morandini, P., Manrique, S., et al. (2016). Live and let die: a REM complex promotes fertilization through synergid cell death in Arabidopsis. Development 143, 2780-2790. doi: 10.1242/dev.134916

Michard, E., Lima, P. T., Borges, F., Silva, A. C., Portes, M. T., Carvalho, J. E., et al. (2011). Glutamate receptor-like genes form Ca2 + channels in pollen tubes and are regulated by pistil D-Serine. Science 332, 434-437. doi: 10.1126/science. 1201101

Miyazaki, S., Murata, T., Sakurai-Ozato, N., Kubo, M., Demura, T., Fukuda, H., et al. (2009). ANXUR1 and 2, sister genes to FERONIA/SIRENE, are male factors for coordinated fertilization. Curr. Biol. 19, 1327-1331. doi: 10.1016/j. cub.2009.06.064

Mizukami, A. G., Inatsugi, R., Jiao, J., Kotake, T., Kuwata, K., Ootani, K., et al. (2016). The AMOR arabinogalactan sugar chain induces pollen-tube competency to respond to ovular guidance. Curr. Biol. 26, 1091-1097. doi: 10.1016/j.cub.2016.02.040

Mollet, J. C., Park, S. Y., Nothnagel, E. A., and Lord, E. M. (2000). A lily stylar pectin is necessary for pollen tube adhesion to an in vitro stylar matrix. Plant Cell 12, 1737-1750. doi: 10.1105/tpc.12.9.1737

Mori, T., Igawa, T., Tamiya, G., Miyagishima, S.-Y., and Berger, F. (2014). Gamete attachment requires GEX2 for successful fertilization in Arabidopsis. Curr. Biol. 24, 170-175. doi: 10.1016/j.cub.2013.11.030

Mori, T., Kuroiwa, H., Higashiyama, T., and Kuroiwa, T. (2005). GENERATIVE CELL SPECIFIC 1 is essential for angiosperm fertilization. Nat. Cell Biol. 8, 64-71. doi: $10.1038 /$ ncb1345

Mosher, S., and Kemmerling, B. (2013). PSKR1 and PSY1R-mediated regulation of plant defense responses. Plant Signal. Behav. 8:e24119. doi: 10.4161/psb.24119

Motomura, K., Berger, F., Kawashima, T., Kinoshita, T., Higashiyama, T., and Maruyama, D. (2016). Fertilization-independent cell-fusion between the synergid and central cell in the polycomb mutant. Cell Struct. Funct. 41, 121-125. doi: 10.1247/csf.16010

Ngo, Q. A., Vogler, H., Lituiev, D. S., Nestorova, A., and Grossniklaus, U. (2014). A calcium dialog mediated by the FERONIA signal transduction pathway controls plant sperm delivery. Dev. Cell 29, 491-500. doi: 10.1016/j.devcel.2014. 04.008

Nguema-Ona, E., Vicré-Gibouin, M., Gotté, M., Plancot, B., Lerouge, P., Bardor, M., et al. (2014). Cell wall O-glycoproteins and N-glycoproteins: aspects of biosynthesis and function. Front. Plant Sci. 5:499. doi: 10.3389/fpls.2014. 00499

Ogawa-Ohnishi, M., and Matsubayashi, Y. (2015). Identification of three potent hydroxyproline Ogalactosyltransferases in Arabidopsis. Plant J. 81, 736-746. doi: $10.1111 /$ tpj. 12764

Okuda, S., Tsutsui, H., Shiina, K., Sprunck, S., Takeuchi, H., Yui, R., et al. (2009). Defensin-like polypeptide LUREs are pollen tube attractants secreted from synergid cells. Nature 458, 357-361. doi: 10.1038/nature07882

Palanivelu, R., Brass, L., Edlund, A. F., and Preuss, D. (2003). Pollen tube growth and guidance is regulated by POP2, an Arabidopsis gene that controls GABA levels. Cell 114, 47-59. doi: 10.1016/S0092-8674(03)00479-3

Palanivelu, R., and Preuss, D. (2006). Distinct short-range ovule signals attract or repel Arabidopsis thaliana pollen tubes in vitro. BMC Plant Biol. 6:7. doi: 10.1186/1471-2229-6-7

Palanivelu, R., and Tsukamoto, T. (2012). Pathfinding in angiosperm reproduction: pollen tube guidance by pistils ensures successful double fertilization. Wiley Interdiscip. Rev. Dev. Biol. 1, 96-113. doi: 10.1002/wdev.6

Park, S. Y., Jauh, G. Y., Mollet, J. C., Eckard, K. J., Nothnagel, E. A., Walling, L. L., et al. (2000). A lipid transfer-like protein is necessary for lily pollen tube adhesion to an in vitro stylar matrix. Plant Cell 12, 151-164. doi: 10.1105/tpc. 12.1.151

Peng, Y.-B., Zou, C., Gong, H.-Q., Bai, S.-N., Xu, Z.-H., and Li, Y.-Q. (2005). Immunolocalization of arabinogalactan proteins and pectins in floral buds of cucumber (Cucumis sativus L.) during sex determination. J. Integr. Plant Biol. 47, 194-200. doi: 10.1111/j.1744-7909.2005.00023.x

Pennell, R. I., Janniche, L., Kjellbom, P., Scofield, G. N., Peart, J. M., and Roberts, K. (1991). Developmental regulation of a plasma membrane arabinogalactan protein epitope in oilseed rape flowers. Plant Cell 3, 1317-1326. doi: 10.1105/ tpc.3.12.1317

Pennell, R. I., Knox, J. P., Scofield, G. N., Selvendran, R. R., and Roberts, K. (1989). A family of abundant plasma membrane-associated glycoproteins related to the arabinogalactan proteins is unique to flowering plants. J. Cell Biol. 108, 1967-1977. doi: 10.1083/jcb.108.5.1967

Pennell, R. I., and Roberts, K. (1990). Sexual development in the pea is presaged by altered expression of Arabinogalactan protein. Nature 344, 547-549. doi: $10.1038 / 344547 \mathrm{a} 0$

Pereira, A. M., Lopes, A. L., and Coimbra, S. (2016a). JAGGER, an AGP essential for persistent synergid degeneration and polytubey block in Arabidopsis. Plant Signal. Behav. 11:e1209616. doi: 10.1080/15592324.2016.1209616

Pereira, A. M., Masiero, S., Nobre, M. S., Costa, M. L., Soliìs, M.-T., Testillano, P. S., et al. (2014). Differential expression patterns of Arabinogalactan Proteins in Arabidopsis thaliana reproductive tissues. J. Exp. Bot. 65, 5459-5471. doi: 10.1093/jxb/eru300

Pereira, A. M., Nobre, M. S., Pinto, S. C., Lopes, A. L., Costa, M. L., Masiero, S., et al. (2016b). "Love is strong, and you're so sweet": JAGGER is essential for persistent synergid degeneration and polytubey block in Arabidopsis thaliana. Mol. Plant. 9, 601-614. doi: 10.1016/j.molp.2016.01.002

Pereira, L. G., Coimbra, S., Oliveira, H., Monteiro, L., and Sottomayor, M. (2006). Expression of arabinogalactan protein genes in pollen tubes of Arabidopsis thaliana. Planta 223, 374-380. doi: 10.1007/s00425-005-0137-4

Pereira, A. M., Pereira, L. G., and Coimbra, S. (2015). Arabinogalactan proteins: rising attention from plant biologists. Plant Reprod. 28, 1-15. doi: 10.1007/ s00497-015-0254-6

Punwani, J. A., and Drews, G. N. (2008). Development and function of the synergid cell. Sex. Plant Reprod. 21, 7-15. doi: 10.1007/s00497-007-0059-3

Qin, Y., Leydon, A. R., Manziello, A., Pandey, R., Mount, D., Denic, S., et al. (2009). Penetration of the stigma and style elicits a novel transcriptome in pollen tubes, pointing to genes critical for growth in a pistil. PLoS Genet. 5:e1000621. doi: 10.1371/journal.pgen.1000621

Qu, L. J., Li, L., Lan, Z., and Dresselhaus, T. (2015). Peptide signalling during the pollen tube journey and double fertilization. J. Exp. Bot. 66, 5139-5150. doi: $10.1093 /$ jxb/erv275

Raghavan, V. (2003). Some reflections on double fertilization, from its discovery to the present. New Phytol. 159, 565-583. doi: 10.1046/j.1469-8137.2003.00846.x

Rotman, N., Rozier, F., Boavida, L., Dumas, C., Berger, F., and Faure, J. E. (2003). Female control of male gamete delivery during fertilization in Arabidopsis thaliana. Curr. Biol. 13, 432-436. doi: 10.1016/S0960-9822(03)00093-9

Samuel, M. A., Chong, Y. T., Haasen, K. E., Aldea-Brydges, M. G., Stone, S. L., and Goring, D. R. (2009). Cellular pathways regulating responses to compatible and self-incompatible pollen in Brassica and Arabidopsis stigmas intersect at Exo70A1, a putative component of the exocyst complex. Plant Cell 21, 2655-2671. doi: 10.1105/tpc.109.069740

Sandaklie-Nikolova, L., Palanivelu, R., King, E. J., Copenhaver, G. P., and Drews, G. N. (2007). Synergid cell death in Arabidopsis is triggered following direct interaction with the pollen tube. Plant Physiol. 144, 1753-1762. doi: 10.1104/ pp.107.098236

Schneitz, K., Hülskamp, M., and Pruitt, R. E. (1995). Wild-type ovule development in Arabidopsis thaliana: a light microscope study of cleared whole-mount tissue. Plant J. 7, 731-749. doi: 10.1046/j.1365-313X.1995.07050731.x

Schultz, C. J., Rumsewicz, M. P., Johnson, K. L., Jones, B. J., Gaspar, Y. M., and Bacic, A. (2002). Using genomic resources to guide research directions: the arabinogalactan protein gene family as a test case. Plant Physiol. 129, 1448-1463. doi: 10.1104/pp.003459

Sedbrook, J. C., Carroll, K. L., Hung, K. F., Masson, P. H., and Somerville, C. R. (2002). The Arabidopsis SKU5 gene encodes an extracellular glycosyl phosphatidylinositolanchored glycoprotein involved in directional root growth. Plant Cell 14, 1635-1648. doi: 10.1105/tpc.002360

Sedgley, M., Blesing, M. A., Bonig, I., Anderson, M. A., and Clarke, A. E. (1985). Arabinogalactan- proteins are localized extracellularly in the transmitting tissue of Nicotiana alata link and otto, an ornamental tobacco. Micron Microsc. Acta 16, 247-254. doi: 10.1016/0739-6260(85)90049-8 
Seifert, G. J., and Roberts, K. (2007). The biology of arabinogalactan proteins. Annu. Rev. Plant Biol. 58, 137-161. doi: 10.1146/annurev.arplant.58.032806. 103801

Shimizu, K. K., Ito, T., Ishiguro, S., and Okada, K. (2008). MAA3 (MAGATAMA3) helicase gene is required for female gametophyte development and pollen tube guidance in Arabidopsis thaliana. Plant Cell Physiol. 49, 1478-1483. doi: 10. $1093 / \mathrm{pcp} / \mathrm{pcn} 130$

Shimizu, K. K., and Okada, K. (2000). Attractive and repulsive interactions between female and male gametophytes in Arabidopsis pollen tube guidance. Development 127, 4511-4518.

Showalter, A. M., Keppler, B., Lichtenberg, J., Gu, D., and Welch, L. R. (2010). A bioinformatics approach to the identification, classification, and analysis of hydroxyproline-rich glycoproteins. Plant Physiol. 153, 485-513. doi: 10.1104/ pp.110.156554

Sprunck, S., Rademacher, S., Vogler, F., Gheyselinck, J., Grossniklaus, U., and Dresselhaus, T. (2012). Egg cell-secreted EC1 triggers sperm cell activation during double fertilization. Science 338, 1093-1097. doi: 10.1126/science. 1223944

Stührwohldt, N., Dahlkea, R. I., Kutschmara, A., Pengb, X., Sunb, M.-X., and Sautera, M. (2015). Phytosulfokine peptide signaling controls pollen tube growth and funicular pollen tube guidance in Arabidopsis thaliana. Physiol. Plant. 153, 643-653. doi: 10.1111/ppl.12270

Suárez, C., Zienkiewicz, A., Castro, A. J., Zienkiewicz, K., Majewska-Sawka, A., and Rodriìguez-Garciì, M. I. (2013). Cellular localization and levels of pectins and Arabinogalactan proteins in olive (Olea europaea L.) pistil tissues during development: implications for pollen-pistil interaction. Planta 237, 305-319. doi: $10.1007 /$ s00425-012-1774-z

Tan, L., Eberhard, S., Pattathil, S., Warder, C., Glushka, J., Yuan, C., et al. (2013). An Arabidopsis cell wall proteoglycan consists of pectin and arabinoxylan covalently linked to an arabinogalactan protein. Plant Cell 25, 270-287. doi: 10.1105/tpc.112.107334

Takeuchi, H., and Higashiyama, T. (2012). A species-specific cluster of defensinlike genes encodes diffusible pollen tube attractants in Arabidopsis. PLoS Biol. 10:e1001449. doi: 10.1371/journal.pbio.1001449

Takeuchi, H., and Higashiyama, T. (2016). Tip-localized receptors control pollen tube growth and LURE sensing in Arabidopsis. Nature 531, 245-248. doi: 10. 1038/nature 17413

Tsukamoto, T., Qin, Y., Huang, Y., Dunatunga, D., and Palanivelu, R. (2010). A role for LORELEI, a putative glycosylphosphatidylinositol-anchored protein, in Arabidopsis thaliana double fertilization and early seed development. Plant J. 62, 571-588. doi: 10.1111/j.1365-313X.2010.04177.x

Tucker, M. R., and Koltunow, A. M. J. (2014). Traffic monitors at the cell periphery: the role of cell walls during early female reproductive cell differentiation in plants. Curr. Opin. Plant Biol. 17, 137-145. doi: 10.1016/j.pbi.2013. 11.015

Tucker, M. R., Okada, T., Hu, Y., Scholefield, A., Taylor, J. M., and Koltunow, A. M. J. (2012). Somatic small RNA pathways promote the mitotic events of megagametogenesis during female reproductive development in Arabidopsis. Development 139, 1399-1404. doi: 10.1242/dev.075390

Tung, C.-W., Dwyer, K. G., Nasrallah, M. E., and Nasrallah, J. B. (2005). Genomewide identification of genes expressed in Arabidopsis pistils specifically along the path of pollen tube growth. Plant Physiol. 138, 977-989. doi: 10.1104/pp. 105.060558

Völz, R., Heydlauff, J., Ripper, D., von Lyncker, L., and Gross-Hardt, R. (2013). Ethylene signaling is required for synergid degeneration and the establishment of a pollen tube block. Dev Cell. 25, 310-316. doi: 10.1016/j.devcel.2013. 04.001

von Besser, K., Frank, A. C., Johnson, M. A., and Preuss, D. (2006). Arabidopsis HAP2 (GCS1) is a sperm-specific gene required for pollen tube guidance and fertilization. Development 133, 4761-4769. doi: 10.1242/dev.02683

Wang, T., Liang, L., Xue, Y., Jia, P. F., Chen, W., Zhang, M. X., et al. (2016). A receptor heteromer mediates the male perception of female attractants in plants. Nature 531, 241-244. doi: 10.1038/nature16975

Webb, M. C., and Williams, E. G. (1988). The pollen tube pathway in the pistil of Lycopersicon peruvianum. Ann. Bot. 61, 415-423.

Wolters-Arts, M., Lush, W. M., and Mariani, C. (1998). Lipids are required for directional pollen- tube growth. Nature 392, 818-821. doi: 10.1038/ 33929

Woriedh, M., Merkl, R., and Dresselhaus, T. (2015). Maize EMBRYO SAC family peptides interact differentially with pollen tubes and fungal cells. J. Exp. Bot. 66, 5205-5216. doi: 10.1093/jxb/erv268

Wu, H., de Graaf, B., Mariani, C., and Cheung, A. Y. (2001). Hydroxyproline-rich glycoproteins in plant reproductive tissues: structure, functions and regulation. Cell Mol. Life Sci. 58, 1418-1429. doi: 10.1007/PL00000785

Wu, H., Wong, E., Ogdahl, J., and Cheung, A. Y. (2000). A pollen tube growthpromoting arabinogalactan protein from Nicotiana alata is similar to the tobacco transmitting tractS protein. Plant J. 22, 165-176. doi: 10.1046/j.1365313x.2000.00731.x

Wu, H. M., Wang, H., and Cheung, A. Y. (1995). A pollen tube growth stimulatory glycoprotein is deglycosylated by pollen tubes and displays a glycosylation gradient in the flower. Cell 82, 395-403. doi: 10.1016/0092-8674(95) 90428-X

Yadegari, R., and Drews, G. N. (2004). Female gametophyte development. Plant Cell 16, S133-S141. doi: 10.1105/tpc.018192

Yang, J., Sardar, H. S., McGovern, K. R., Zhang, Y., and Showalter, A. M. (2007). A lysine-rich arabinogalactan protein in Arabidopsis is essential for plant growth and development, including cell division and expansion. Plant J. 49, 629-640. doi: 10.1111/j.1365-313X.2006.02985.x

Zinkl, G. M., Zwiebel, B. I., Grier, D. G., and Preuss, D. (1999). Pollen-stigma adhesion in Arabidopsis: a species-specific interaction mediated by lipophilic molecules in the pollen exine. Development 126, 5431-5440.

Conflict of Interest Statement: The authors declare that the research was conducted in the absence of any commercial or financial relationships that could be construed as a potential conflict of interest.

Copyright (c) 2016 Pereira, Lopes and Coimbra. This is an open-access article distributed under the terms of the Creative Commons Attribution License (CC BY). The use, distribution or reproduction in other forums is permitted, provided the original author(s) or licensor are credited and that the original publication in this journal is cited, in accordance with accepted academic practice. No use, distribution or reproduction is permitted which does not comply with these terms. 